\title{
Identifying the value co-creation behavior of virtual customer environments using a hybrid expert-based DANP model in the bicycle industry
}

Huan-Ming Chuang ${ }^{1}$ and You-Shyang Chen ${ }^{2 *}$

\author{
* Correspondence: \\ ys_chen@cc.hwh.edu.tw \\ 2Department of Information \\ Management, Hwa Hsia University \\ of Technology, 111, Gong Jhuan \\ Rd., Chung Ho District, New Taipei \\ City 235, Taiwan \\ Full list of author information is \\ available at the end of the article
}

\begin{abstract}
Since 2008, soaring international oil prices and environmental awareness have pushed bicycle to be a green transport vehicle to reduce greenhouse gas emissions as a significant global trend. Consequently, Taiwan's bicycle industry earned the "bicycle kingdom" has entered a new peak period of demand under popular social trends of bicycling for health conscious and a healthy exercise tool; thus, to co-create value with customers to retain the reputation is important for Taiwan's bicycle industry. In Internet age, plus the prevailing of service-dominant logic, virtual customer environments (VCEs) can be greatly leveraged to promote customers' active engagement in the value co-creation activities. After an extensive literature review, this study organizes a hybrid expert-based DANP model based on the applications of multi-criteria decision making (MCDM) tools, such as decision-making trial and evaluation laboratory (DEMATEL)-based analytical network process (ANP), for investigating the iterative and dynamic nature of customer's engagement and value co-creation behavior in the key bicycle industry in Taiwan. In the empirical study of analysis, the use and gratification framework of prior studies is validated on concerning the dynamic value co-creation behavior in bicycling VCEs and yields the following empirical results: (1) Tribal behavior drives the pursuit of realized benefits through VCE engagement and affects the related participation and citizenship behaviors in turn; (2) recognize the importance of social influences toward personal commitment and engagement of bicycling activities and related VCEs; and (3) four broad types of interaction-based benefits derived from engagement in VCEs include cognitive, social integrative, personal integrative, and hedonic benefits. The major research findings on theoretical implications and managerial implications provide helpful insights on marketing of Taiwan's bicycle industry.
\end{abstract}

Keywords: Service-dominant logic; Virtual customer environment; Value co-creation; Customer engagement; DANP model

\section{Introduction}

Based on a summarization report from "my Management Knowledge Center" (http://mymkc.com/articles/contents.aspx?ArticleID=21675), Taiwan's bicycle industry has information-rich on the developments and status. Taiwan's bicycle industry has developed more than 30 years and won the "bicycle kingdom" in the international arena. Due to threaten by low price competitions from China, Vietnam, and other less-developed countries, as well as the relocation of manufacturers and other factors, the industry began to decline. To face and overcome these challenges, Taiwan's bicycle industry in the 1990s

\section{Springer}


actively implements restructuring, emphasizes on innovative research and development, and develops high value-added product with own brand. In 2003, two big companies in bicycle industry, Giant and Merida co-sponsored an "A-team" initiative, hoping to provide high value-added products through differentiation strategy and by integrating whole bicycle supply chain for collaborative learning and technological enhancements.

Since 2008, soaring international oil prices and environmental protection awareness have pushed bicycle to be a green transport vehicle to reduce greenhouse gas emissions as a significant global trend. Consequently, Taiwan's bicycle industry has reached a new peak performance. Furthermore, on January 1, 2011, the cross-strait "economic cooperation framework agreement (ECFA)" came into effect, which puts bicycle in the early harvest list with relative tax incentives (i.e., $6 \%$ tariff for export and 13\% for import). Therefore, it is beneficial for Taiwan to marketing high-end bicycles to mainland China and greatly reducing threatens from China's dumping back of low-priced bicycles. Although Taiwan's competiveness in bicycle industry is protected temporally, this industry still needs to confront with an extensive global competition. It is great issues for them to keep and discuss creating value for customers to increase an extensive global competitiveness.

In the context of current service economy era, service is an essential weapon for creating customer value. Vargo and Lusch [1] proposed the "service-dominant (S-D) logic" perspective to transcend traditional "goods-dominant (G-D) logic." S-D logic emphasizes the interactive and networked nature of value co-creation with customers. This orientation is clearly presented in related foundational premises (FPs) of S-D logic [2]. For example, FP6 states "The customer is always a co-creator of value", which implies value co-creation is interactional. In addition, FP8 indicates "A service-centered view is inherently customer-orientated and relational," because service values are determined by customers' perceptions in the value co-creation activities. Last, FP2 denotes "Indirect exchange masks the fundamental basis of exchange", which emphasizes service provided through complex combinations of goods, money, and institutions; therefore, it has network in nature. Particularly, under the S-D logic and the rapid developments of information and communications technologies (ICTs), virtual customer environments (VCEs) have been widely adopted as mechanisms for enhancing customers' value co-creation activities.

According to the studies of [3,4], VCEs are brand communities of interests, such as customers, to unite around specific products or services. Furthermore, the interaction in VCEs is at least partially supported by technology and guided by norms [5]. The vast variety and amount of services provided by VCEs ranging from online discussion forums to virtual design and prototyping centers enable firms to involve their customers in product design, testing, and support related activities [3,4,6]. Such platforms exhibit significant strategic importance for managing customer value co-creation networks under S-D logic [1]. Take Taiwan's bicycling industry as an example: Giant and Merida have all established and well-managed their VCEs, such as fans clubs in Facebook, to facilitate active customer engagement relating to bicycling issues. There are rich fabricating elements for the configuration and management of VCEs. Based on literature of the strategic management and quality management, researchers have identified five major roles for customers in value co-creation: Operant resource, co-producer, buyer, user, and product [3,7]. In addition, underlying themes and related design parameters might include customer 
interaction pattern, customer knowledge creation, customer motivation, and VCE and new product development integration [3]. As a result, the complicated interrelationships among related elements in VCEs as value co-creation networks deserve extensive investigations to gain insights on leveraging this powerful platform.

Related issues in VCEs have been studied well. For example, Nambisan [3] investigated the design issues of VCEs for new product development, Algesheimer et al. [8] examined the social influence of brand community, Nambisan and Baron $[4,6]$ explored the interactions in VCEs for value co-creation activities, and [5] stressed on the impact of customer endorsements on information-based behavioral outcomes. Nevertheless, most of these researches are quantitative in nature and rely on traditional methodologies, such as structural equation modeling (SEM) that needs to make assumptions about specific cause-effect relationships between constructs before validation. Given the above shortcomings, this study applies multi-criteria decision making (MCDM) tools instead of the desired feature of relieving the constraint for prior assumptions to provide complementary insights on the complicated, dynamic, and iterative VCE's issues.

Four major research objectives of this study are listed as follows. (1) Identify the motivating factors for driving customers participate voluntarily in value co-creation activities in bicycling VCEs. (2) Investigate potential benefits acquired from active engagement in bicycling VCEs. (3) Explore the dynamic nature value co-creation activities in bicycling VCEs, specifically for the interplay of customer participation behavior and customer citizenship behavior. (4) Suggest strategies for designing and prompting bicycling VCEs to be maximally appealing to potential contributors.

\section{Literature review}

This section reviews related literatures, including service-dominant logic and customer engagement of the iterative and dynamic nature of customer engagement behavior, virtual customer environments of the nature of the platform, tribal behavior of customers' motivations to engage in VCEs and the realized benefits engaged in VCEs, and customer participation behavior and customer citizenship behavior on customer value co-creation behaviors.

\section{Service-dominant logic and customer engagement}

The value co-creation behavior conducted in VCEs greatly relates with concepts of traditional goods-dominant, service-dominant logic, customer engagement, and relationship marketing; thus, it is necessary to review them in turn.

\section{From goods-dominant logic to service-dominant logic}

Vargo and Lusch [1] and Lusch, Vargo, and Wesseles [9] emphasized the differences between operand and operant resources. (1) Operand resources: They are those on which an operation or act is performed to produce an effect [10], and they are usually static and inert and have been highly treasured for wealth creation and exchange. Under this background, G-D logic is developed to put primary concerns on operand resources. Major features of G-D logic are described as follows: (a) People exchange for goods (operand resources) as end products; (b) the customer (as an operant resource) is the recipient of goods and "something to be marketing to"; (c) value is determined by the producer and embedded in goods (operand resources) represented by pricing; (d) 
source of economic growth is reflected in the accumulation of operand resources [1,9]. (2) Operant resources: Operand resources require other dynamic and infinite resources, called operant resources, to make them useful and valuable [9]. Operant resources are resources that produce effects [10], capable on acting on operand resources (and other operant resources), and often intangible, such as knowledge and skills [9]. As knowledge and skills were recognized as the most important types of resources in late twentieth century, the role of operant resources began elevating.

Particularly, Vargo and Lusch [1] further formally articulated the S-D logic as a transcendent perspective over traditional G-D logic. In contrast to G-D logic, major characteristics of S-D logic are summarized as follows: (1) People exchange to acquire service (the benefits of operant resources), and goods are transmitters of operant resources; (2) the customer (as an operant resource) is a co-producer of service, participating actively in relational exchange and co-production, and whom the marketer "marketing with"; (3) value is perceived and determined by the customer on the basis of "value in use", and organizations can only make value propositions; and (4) economic growth is obtained through the application and exchange of operant resources (e.g., knowledge and skills) [1,9].

\section{Customer engagement}

Due to rapid developments of ICTs and globalization of market, customers can easily establish or join communities to communicate with each other rather than being silent and isolated ones. This information motivates companies to discovering new ways to engage their customers for the purpose of creating and sustaining emotional connection with the brand. Vivek, Beatty, and Morgan [11] stressed the "beyond purchase" nature of customer engagement (CE), which is individuals who engage with the brand without necessarily purchasing related intention, such as search, alternative evaluation, and brand choice. They defined CE as "the intensity of an individual's participation in and connection with an organization's offerings and/or organizational activities, which either the customer or the organization initiate." Under this definition, different perspectives exist. (1) From the organization's viewpoint, CE is activities facilitating "repeated interactions that strengthen the emotional, psychological or physical investment a customer has in a brand" [12]. (2) Restated, CE refers to "the intensity of customer participation with both representatives of the organization and with other customers in a collaborative knowledge exchange process" [13] from the perspective of customer.

To explore the theoretical foundations of CE, Brodie, Hollebeek, Juric, and Ilic [14] relied on relationship marketing theory and the S-D logic, to propose five fundamental propositions (FPs) that can help developing framework for further research to get deeper insights and refinements of the conceptual domain of CE. The FPs is summarized in three dimensions of people, environment, and behavior, suggested by social cognitive theory [15]. For example, FP1 - CE reflects a psychological state, which occurs by virtue of interactive customer experiences with a focal agent/object within specific service relationships.

\section{Incorporating customer engagement with relationship marketing}

There is a major shift in marketing practice: From mass marketing (or transaction marketing) to relationship marketing (RM) [16]. The RM is originally defined as 
"establishing, developing, enhancing, and maintaining successful relational exchanges" [17]. Although this broad conceptualization of RM keeps balance view on attracting new customers and retaining existing customers, subsequent RM research has been concentrated on the enhancement and retention of existing customers in buyer-seller relationships based on exchange [11]. Nevertheless, recent proposition of S-D logic [1,2] and writings of [18-20] suggested that RM research should address the interactive, co-creative experiences of both existing and potential customers. Furthermore, Vivek, Beatty, and Morgan [11] recognized the importance of incorporating CE with RM and named the perspective as "expanded domain of relationship marketing" (i.e., expanded relationship marketing). The expanded RM interacts as "value configurations" among organizations, organizational networks, and existing and potential customers, driven by interested parties in a value-creation virtual network.

\section{Virtual customer environment}

Following the rapid development of network technology, the Internet is penetrating almost every aspect of life. One significant phenomenon is the widespread and popularity of VCEs that redefine the role customers plays in value co-creation. The VCE platforms have strategic significance to co-opt customer competencies for value co-creation [1]. It is evident that based on examples from different industries, firms can derive different and tremendous benefits from managing successful VCEs [6,21]. Porter et al. [5] indicated three main types of VCEs: (1) Third-party managed, (2) firm sponsored, and (3) customer initiated. Basic profiles of them are described as follows. (1) Third-party-managed VCEs are typically hosted and managed by neutral organizational entities that connect members for the exchange of information or products. (2) A firm-sponsored VCE is established by a single firm and often embedded on the firm's own website, for the purpose of fostering relationship with customers, facilitating peer support and service among customers, gaining marketplace insights, and enhancing profitability. (3) Customer-initiated VCEs are organized by individual members to interact around a shared interest, such as products and/or brands. Members generally establish an independent website or rely on a hosting service to operate the community.

\section{Tribal behavior}

There exists significant interrelationship between brands and consumers [22]. Veloutsou [23] identified two types of relationships that consumer develops around brands. The first type is the direct relationships between the brand and consumers, while the second is the links that consumers develop with other consumers around the brand. There is an impulse for a brand admirer to joint groups that focused on the focal brand to interact with other consumers. These groups have been described as brand community, brand tribes, or brand sub-cultures of consumption [23,24]. Brand communities are defined as "formal brand related groups which consist of individuals who join the group willingly and acknowledge their membership of the brand" [25]. In contrast, brand tribes are groups of individuals that exhibit tribal behavior; that is, participants have not necessarily joined the group formally, but they demonstrate a passion toward the brand tribe [26]. Therefore, brand tribes have informal and wider membership than brand communities [25], with a sense of togetherness and belonging [27]. 
Consumer behavior within brand tribes has attracted recent attention in marketing fields. It has been conceptualized in various ways [28]. Motivated by the lack of a general measurement instrument for measuring tribal behavior, Tsiotsou and Veloutsou [28] developed a scale named TRIBE, which operationalizes tribal behavior via four dimensions, namely collective memory, reference group acceptance, brand tribe identification, and brand tribe engagement. (1) Collective memory denotes the brand knowledge that the consumers are developing and willing to share this knowledge with other group members [29]. (2) Reference group acceptance refers to the perceived approval of brand related activities by other people in their reference group [29]. (3) Brand tribe engagement is the degree of motivation in active participation in the brand group related activities [8]. (4) Brand tribe identification is the perceived attachment of an individual to other brand supporters [8]. Similarly, Veloutsou and Moutinho [29] identify five major dimensions of tribal behavior, including degree of fit with lifestyle, passion in life, social visibility, and the same reference group acceptance and collective memory. The degree of fit with lifestyle represents the degree of fit between specific brand and customer; the passion in life means that the brand has special meaning for customers; and the social visibility denotes popularity of the brand in society. In sum, these dimensions are categorized into three classifications: "Personal factors" (i.e., degree of fit with life style and passion in life), "social influences" (i.e., reference group acceptance, collective memory, and social visibility), and "VCE identification and engagement" (i.e., VCE identification and VCE engagement).

\section{Perceived customer benefits in VCEs: Uses and gratifications framework}

The uses and gratifications (U\&G) framework [30] identifies four broad types of benefits, including cognitive benefits, social integrative benefits, personal integrative benefits, and hedonic benefits, which individuals can derive from media usage. According to Nambisan and Baron [6], one common theme of U\&G framework in related studies is their focus on consumers' interactions (with the media itself and others) in a particular context, and how these interactions gratify their different needs or create gratification opportunities [31]. Recent application contexts of this framework to VCEs show that though specific benefits may vary to different contexts, the essential theoretical assumptions and the broad categories are stable [6]. Therefore, the U\&G framework is properly applied to the context of customer engagement in the VCEs in this study.

The four benefits are identified as follows. (1) Cognitive benefits relate to information acquisition and reflect better understanding of product-related learning regarding product technologies, market, and usage under the context of the VCEs. Thus, VCEs offer opportunities for this kind of learning because they store valuable accumulated knowledge on the product, and this knowledge keeps up to date through continued customer interactions for contribution and sharing [32,33]. (2) Social integrative benefits refer to strengthen the emotional bonds with other community members. In a VCE, the social context is shaped by interactions among participating customers and members of the host firm. Hence, social integrative benefits represent those realized from the social and relational bonds developed over time among the participating parties in the VCEs [3,6]. (3) Personal integrative benefits represent the rewards of achieving a sense of 
self-efficacy and elevated personal status or reputation [30]. VCEs offer the opportunity for individual customer to contribute their product-related knowledge and problemsolving capabilities, thereby enhance their professional and skillful status between peer customers and members of host firm [33]. (4) Hedonic benefits denote the experience related to the concept of flow. Customers' interactions in the VCEs can be a source of highly aesthetic, interesting, pleasurable and mentally stimulating experiences [6]. Customers derive tremendous pleasures from interacting with others concerning the features and the usage of product [34].

\section{Customer participation behavior}

Management literature distinguishes between employee's in-role and extra-role behavior that relates to individual's task performance and context performance separately [35]. Task performance involves behaviors that are expected and necessary for the successful completion of specific task, having in-role in nature. Conversely, context performance involves voluntary and discretionary behaviors, which is extra-role in nature and often refers to organizational citizenship behavior (OCB). In a similar vein, research in customer value co-creation identifies two types of behaviors: (1) Customer participation (in-role) behavior is necessary for a successful value co-creation; (2) alternatively, customer citizenship behavior (extra-role) is voluntary and contributes extraordinary value for value co-creation [36-38]. Empirical studies show there are different antecedents and consequences for in-role and extra-role behaviors [37,38]. Three dimensions: Information seeking, responsible behavior, and personal interaction, in customer participation behavior are determined as follows, and customer citizenship behavior is further explored in next subsection.

\section{Information seeking}

Since product or service-related benefits are major drivers for customer to engage in VCEs, information seeking becomes an important customer participation behavior. Kellogg, Youngdahl, and Bowen [39] identified four distinct forms of customer participation: Preparation, information exchange, relationship building, and intervention. Preparation refers to preparing for the service by such actions as seeking referrals, researching competitors and arriving early; information exchange denotes providing and seeking information to clarify service exchange expectations and seek status. The above two activities relate to information seeking that can help customers to be more proficient value co-creators. Customers seek information for two major purposes [37] in the value co-creation process. First, information seeking reduces customers' uncertainty and enables them to understand and control co-creation environment better. Second, information seeking enhances customers' ability to master their role as co-creator in the value co-creation network.

\section{Responsible behavior}

The second dimension to participation concerns is identified by [40] as responsible behavior. This concept reflects the core nature of value co-creation network that participative parties have their duties and responsibilities. In the service encounter context, customers may need to play the role of partial employees, and employees may need to play the role of partial customers. They have to be responsible and 
behave as such [40]. Customers have to observe rules and policies and accept directions from employee [41]; without customers' responsible behavior, little value co-creation is realized [37].

\section{Personal interaction}

The third dimension of personal interaction participation, identified by [40], refers to interpersonal relations between customers and employees [37]. With the dimensions of service quality, other than environment quality and outcome quality, personal interaction is emphasized as functional quality [42], which is broad and encompass a range of elements that characterize the nature of relationships, such as trust, reliability, support, cooperation, flexibility, commitment [40], courtesy, friendliness, and respect [37]. This factor is important, because in many service encounters the relationship with individual employee may be as significant as the relationship with the organization as a whole [43]. Furthermore, value co-creation takes place in a social setting. The more pleasant, congenial, and positive the social environment is, the more likely customers are willing to engage in value co-creation [44].

\section{Customer citizenship behavior}

Four major customer citizenship behaviors are identified, namely knowledge sharing, advocacy, helping, and continuance intention, as follows.

\section{Knowledge sharing}

According to Alavi and Leidner [45], knowledge is the information processing that takes place in human minds, as well as personalized information related to facts, procedures, concepts, interpretations, ideas, observations, and judgments. Davenport and Prusak [46] defined knowledge sharing as processes that involve exchanging knowledge between individuals and groups. An individual imparts his or her understanding, expertise, or insight to another individual so that the recipient may acquire and leverage the knowledge to create more values. Knowledge sharing lies at the core of continuous improvement processes and is quintessential in terms of transforming an individual's process improvements into actual learning. Clearly, active knowledge sharing requires the willingness of individual member to provide spontaneous assistance without assurance of reciprocation, which relates greatly with customer citizenship behavior. In knowledge management context, sharing knowledge with others without expectation of return represents altruistic behavior. The contributors participate conscientiously and actively (courtesy) with civic virtue and tolerating the efforts of resources given (sportsmanship) when sharing knowledge. Thus, knowledge sharing behavior in VCEs is viewed as a typical customer citizenship behavior. Organ and Konovsky [47] identified five types of OCB: (1) Altruism, voluntary actions, helps another person with work-related problems; (2) conscientiousness goes well beyond the required levels of responsibility; (3) civic virtue has responsible and constructive involvements in the political process of an organization; (4) sportsmanship tolerates the inevitable inconvenience and impositions of work without complaining; and (5) courtesy provides advance notice to people who need such information. Furthermore, knowledge has been widely studied in various application fields, such as web [48,49] and system [50-52]. 


\section{Advocacy}

Advocacy (or word-of-mouth; WOM) refers to recommending the business to others such as friends or family [53]. Positive WOM is often created by loyal customers, and it contributes greatly to a positive reputation of a firm beneficiary for the promotion of its products and services, thereby increases its customer base size [41,53]. The importance of WOM has long been emphasized by marketing researchers and practitioners for a number of reasons. For example, it has been shown to have a significant favorite impact on consumer's purchasing decisions [54] and post-purchase product evaluations [55]. In general, WOM has been shown to be more effective than traditional marketing tools, such as advertising or personal selling, as it is deemed with higher credibility, empathy, and relevance to customers [56]. Particularly, the Internet has emerged as a platform for the popularization of electronic WOM (eWOM) communication for customers [57], and eWOM has thus been examined extensively. Bickart and Schindler [56] proved that product information on VCEs has greater credibility, relevance and more likely to arouse empathy with consumers than information on marketer initiated website content. In the [57] investigation on factors motivating consumers to engage in VCEs and eWOM, they found that major motivations of eWOM participants are similar to those of traditional WOM participants. Such findings suggest the impact of eWOM can be referred to WOM effects; thus, WOM mechanism acts in the same way in VCEs. In the context of value cocreation in VCEs, WOM represents loyalty toward other parties (i.e., the service provider, other members, or the VCE itself) and promotion of their interests beyond personal interests [41]; undoubtedly, it therefore relates to customer citizenship behavior.

\section{Helping}

Helping denotes customers behavior aimed at supporting other customers [37]. In a service co-creation process, customers usually exhibit helping behavior toward other customers other than toward employees because other customers in a service encounter may need help from those with consistent with their expected roles [53]. In addition, customers' roles are less defined and role-scripted, as compared with those of employees'; thus, customers generally need spontaneous help from peer customers [53]. Rosenbaum and Massiah [58] noted that customers have the tendency to recall their own difficult experiences and build a strong sense of empathy and social responsibility to help other customers facing similar difficulties. Just like electronic commerce (EC) taking several forms depending on the degree of digitalization, such as brick-and-mortar, click-and-mortar, and pure-play organizations, the customer citizenship behavior is extended beyond VCEs to physical world, such as get-together and lending a helpful hand.

\section{Continuance intention}

Broadly, the extra-role nature of citizenship behavior may also implies membership continuation intention, which is member's willingness to stay committed, maintain emotional bonds, and finally exhibit intentions to maintain membership with the community [8]. Continuance intention can be referred to the actual intention to continue using the Internet services in the post-adoption stage [59]. 


\section{Methods and materials}

This section describes the development of the research framework, data sampling, and analysis methodology.

\section{Research framework}

Based on the well-known Stimulus-Organism-Response (S-O-R) model, which posits that environmental factors act as stimuli that affect an individual's cognitive and affective reactions, which in turn affect behavior [60], this study proposes a research framework that relates members' tribal behavior with stimuli, perceived benefits from VCE with organism, and value co-creation behavior with response, as shown in Figure 1 below.

\section{Definition of research constructs}

The subsection introduces four major dimensions used in the research framework, including tribal behavior, perceived customer benefits, customer participation behavior, and customer citizenship behavior.

\section{Tribal behavior}

Bicycling enthusiasts' motivations for the sport and their intention to join related VCEs are emphasized in this study first. According to the literature [28,29], the tribal behavior dimension is termed as " $\mathrm{A}$ ", and Table 1 summarizes its criteria and norms.

\section{Perceived customer benefits}

Accordingly, the dimension of perceived customer benefits is derived from U\&G theory $[4,6]$, operationalized, and explained. The perceived customer benefits dimension is termed as "B", and Table 2 summarizes its criteria and norms.

\section{Customer participation behavior}

The in-role dimension of customer value co-creation behavior as customer participation behavior [37] is defined. The customer participation behavior dimension is termed as "C", and Table 3 lists its criteria and norms.

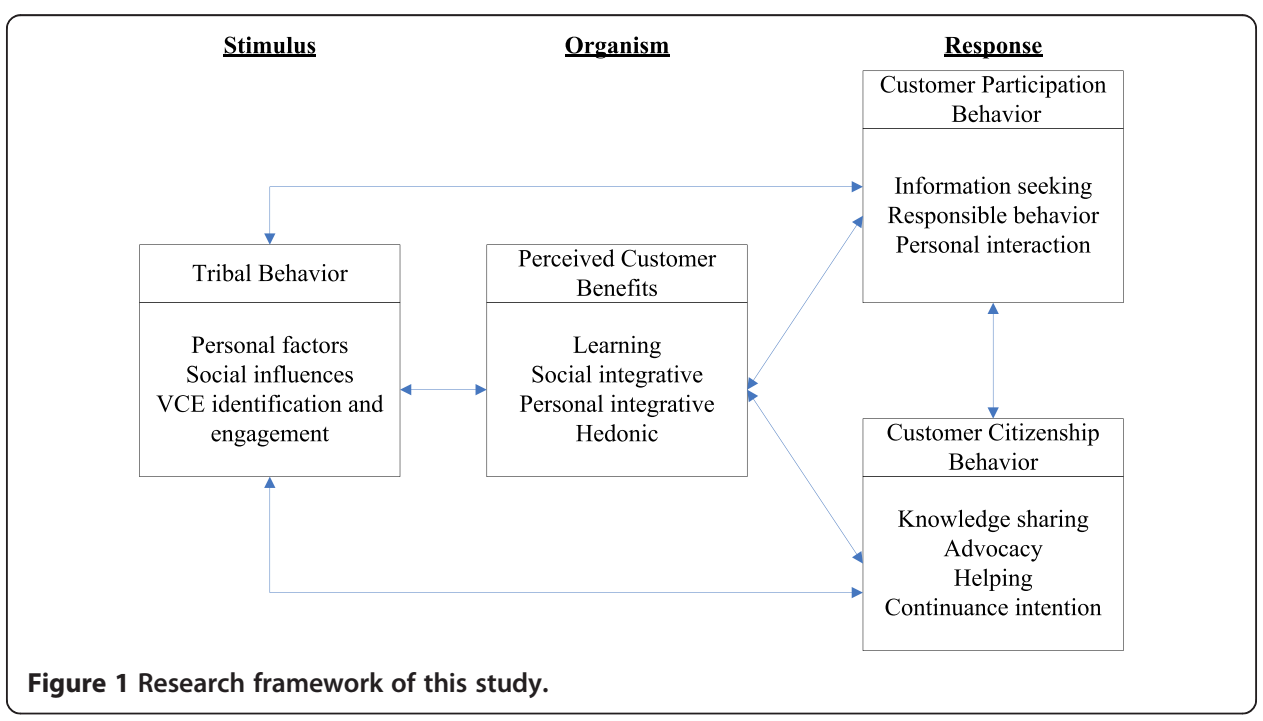


Table 1 Information of tribal behavior dimension

\begin{tabular}{ll}
\hline Criteria & Definition \\
\hline (a1) Personal factors: & Bicycling fits personal life style. \\
Fit with life style & \\
Passion in life & Bicycling contributes to the emotional life of person. \\
(a2) Social influence: & Bicycling is recognized by personal friends and relatives. \\
Reference group acceptance & \\
Social visibility & Bicycling is popular and witnessed in everywhere. \\
Collective memory & People's consensus on the significant sense of bicycling. \\
(a3) VCE identification and engagement: & The person construes himself/herself to be a member \\
VCE identification & belonging to the VCE. \\
VCE engagement intention & The member's intrinsic motivation interacts and cooperates \\
& with other VCE members. \\
\hline
\end{tabular}

\section{Customer citizenship behavior}

The final extra-role dimension of customer value co-creation behavior as customer citizenship behavior [8,37] is also identified, which is termed as " $\mathrm{D}$ ", and Table 4 lists its criteria and norms below.

\section{Research methodology}

This subsection describes research tools and instruments, research subjects and sampling.

\section{Research tools and instruments}

Based on the [14] investigation within the social science and management disciplines, they recognized the dynamic nature of customer engagement process, which is characterized by specific cyclical, iterative dynamics. They identified specific $\mathrm{CE}$ relational consequences that may extend to play the role of antecedents in subsequent $\mathrm{CE}$ processes, revealing the iterative nature of the CE processes over time. Similarly, members of bicycling VCE might be motivated by either one of three constructs (i.e., personal factors, social influences, and VCE identification and engagement) on tribal behavior dimension first, and then the driving dimension can either influence or be influenced by other dimensions.

Traditional methodologies, such as SEM method, need to make assumptions about specific cause-effect relationships between constructs before validation. Consequently, tools, such as decision-making trial and evaluation laboratory (DEMATEL) and analytical network process (ANP), seem more appropriate to explore the dynamic and iterative CE

Table 2 Information of perceived customer benefits dimension

\begin{tabular}{ll}
\hline Criteria & Definition \\
\hline (b1) Learning & $\begin{array}{l}\text { Benefits derived from better understanding and knowledge about the bicycle, } \\
\text { the underlying technologies, and the usage. }\end{array}$ \\
(b2) Social integrative & $\begin{array}{l}\text { Benefits derived from the social and relational bonds with other VCE members } \\
\text { developed over time, such as enhancement of a sense of belonging or social identity. }\end{array}$ \\
(b3) Personal & $\begin{array}{l}\text { By contributing bicycle-related knowledge and problem-solving skills, members achieve } \\
\text { integrative }\end{array}$ \\
a sense of self-efficacy and elevate personal expertise-related status or reputation. \\
(b4) Hedonic
\end{tabular}


Table 3 Information of customer participation behavior dimension

\begin{tabular}{ll}
\hline Criteria & Definition \\
\hline (c1) Information seeking & $\begin{array}{l}\text { VCE members ask directly or observe the behavior of other knowledgeable } \\
\text { or experienced members. }\end{array}$ \\
(c2) Responsible behavior & $\begin{array}{l}\text { Participative members recognize their duties and responsibilities in value } \\
\text { co-creation. }\end{array}$ \\
(c3) Personal interaction & $\begin{array}{l}\text { Good interpersonal relations among VCE members are necessary for } \\
\text { successful value co-creation. }\end{array}$ \\
\hline
\end{tabular}

behavior than traditional methodologies when facing MCDM problems. Major desirable features of the mathematical tools are relied on extensive pairwise comparisons among system elements without prior assumptions about their relationships. In this study, we don't enforce any prior assumptions on the relationships among dimensions and criteria. Subsequently, the final influence pattern (directions and degrees) will be objectively derived by mathematic calculations through DANP method instead of subjectively judgments. By this way, this study can contribute insightful and complementary findings to this research application field.

Generally, research instrument is developed in three major parts. (1) First part collects basic information of interviewees. (2) Second part provides detailed definitions and examples of all research constructs. (3) Last part invites interviewees to make extensive pairwise comparisons among all constructs. In detailed processes, the interviewees first decide the most appropriate relationship between two constructs from four possible influences, such as " $x$ " (No relationship), " $\rightarrow$ " (X influences $Y$ ). “ they denote degree of influences from five possible levels: $0,1,2,3$, and 4 to represent "No influence", "Very low influence", "Low influence", "High influence", and "Very high influence", respectively. Pairwise relative comparison is the essential processing of analytical hierarchy process (AHP) and ANP, which allow decision maker to set priorities and make choices on the basic of their objectives and knowledge and experiences in a way that is consistent with their intuitive thought process [61]. With the pairwise comparison, weights and priorities are not arbitrarily assigned, but are derived from a set of redundant judgments. This method for deriving the priorities is good, because first, it is based on a sound mathematical foundation, and second, validation studies have also been performed [61].

\section{Research subjects and sampling}

The population of this study is bicycling enthusiasts who engage bicycling related VCEs actively. They are samples by this study under principles described below to meet both

\section{Table 4 Information of customer citizenship behavior dimension}

\begin{tabular}{|c|c|}
\hline Criteria & Definition \\
\hline (d1) Knowledge sharing & $\begin{array}{l}\text { The willingness of individual member is to provide spontaneous bicycle-related } \\
\text { assistance without assurance of reciprocation. }\end{array}$ \\
\hline (d2) Advocacy & $\begin{array}{l}\text { Recommend the VCE to other friends or relatives and promote the VCE's } \\
\text { interests beyond personal interests. }\end{array}$ \\
\hline (d3) Helping & Member behavior aims at assisting other members. \\
\hline (d4) Continuance intention & $\begin{array}{l}\text { The member's intentions maintain membership and bonds to the VCE in the } \\
\text { future, implying willingness to stay commitment to the VCE. }\end{array}$ \\
\hline
\end{tabular}


qualitative and quantitative criteria. For qualified research subjects, Northcutt and McCoy [62] suggested desirable characteristics of members for proper compositions of focus group are summarized as follows: (1) They are knowledgeable of, and experience with the research issue; (2) they have the ability to ponder the question and to express their thoughts into word adequately; (3) they have motivation and time to participate in the study; (4) they are homogeneous concerning important dimensions of distance and power; and (5) they have good team spirit, and they are neither overpowering nor too timid to speak. In other words, regarding quantitative requirements, Denzin and Lincoln [63] proposed that the size of sample is not so important as sample's appropriateness and richness. Therefore, this study follows above suggestions to recruit research subjects from active members form bicycling VCEs who have long-term enthusiasm toward bicycling. Consistent with the principles of snowball sampling and theoretical saturation, appropriate sample size is determined. That is, we sample subjects until we believe that no more new information can be found. Theoretical saturation means that no new or relevant data emerge concerning a category, that the category is well-developed, and that the linkage between categories are well-established [64].

The theoretical saturation of this study is evaluated by "errors of gap ratio" (EGR) as formatted below [65], which has consistency index in analytic hierarchical process:

$E G R=\frac{1}{n(n-1)} \sum_{i=1}^{n} \sum_{j=1}^{n} \frac{\left|a_{i j}^{p}-a_{i j}^{p-1}\right|}{a_{i j}^{p}} \times 100 \%$, where $p$ denotes the number of sample, and $a_{i j}^{p}$ is the average influence of $i$ criteria on $j$; and the number of gap ratio elements is $n(n-1)$. When EGR is $\alpha$, the significant confidence is $(1-\alpha)$. In general, we have over $95 \%$ confidence to contend that there is no significant differences between evaluations of sample size $p$ and $p-1$ when $\alpha$ is less than $5 \%$. Consequently, it is reasonable to propose that sample size $p$ is significantly close to theoretical saturation and qualified to be an appropriate size. Accordingly, we will conduct the survey in face-to-face manner to make sure surveyed experts understand real meanings of research constructs, though detailed definitions and examples of them were well prepared and presented in the questionnaire too. Subjects were asked to do comprehensive pairwise comparisons regarding all research constructs to evaluate their effects and influences.

\section{Building a DANP model for exploring the dynamics of customer value co-creation behavior}

Particularly, intelligent hybrid systems integrate several models for processing real-world problems [66-70]. In practice, such a hybrid model outperforms stand-alone models for that the intelligent hybrid model maximizes their advantages while minimizes the limitations. This study, therefore, builds a hybrid DEMATEL-based ANP method called DANP model, which identifies the interdependence among the dimensions and criteria based on intelligent methods. Figure 2 illustrates the proposed model by applying core of DEMATEL and ANP methods that are an organization of DEMATEL and ANP in turn. (1) The DEMATEL approach is a mathematical procedure originated from the Geneva Research Centre of the Battelle Memorial Institute designed to deal with important issues of world societies and possess some excellent features [71,72], which is based on matrices to represent the contextual relation as well as strength of influence of the elements of the target system, and it can convert the cause-effect 


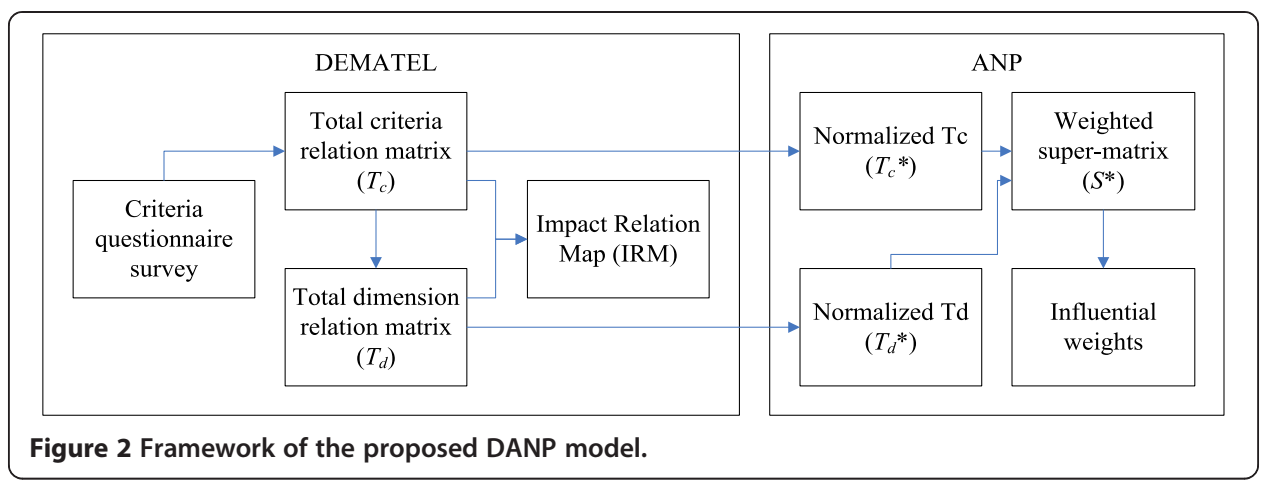

relationship of elements into visible structural models. Due to owning practical benefits, the DEMATEL has been widely applied in various fields, such as marketing [73,74], education [75,76], investment [77], and supply chain management [78]. (2) Saaty [79] established an ANP way for determining complicated nonlinear network relationships to diminish the limitations that AHP hypothesizes all factors of indices under the frame work of each level possessing mutual independences. Nevertheless, a limitation is the survey questionnaire of ANP too laborious to fill out $[80,81]$. To solve this problem, we based on the concepts of total criteria matrix and total dimensions matrix generated by DEMATEL technique to conduct further procedures required by ANP method to deal with problems of dependence and feedback among criteria, which is DANP model.

\section{The algorithm of DANP}

The algorithm steps of the proposed DANP model for building an impact relation map (IRM) using DEMATEL technique and for finding influential weights by ANP technique are summarized in detail as follows.

\section{Step-1 Crate the initial direct-relation matrix}

Acquire the assessments about direct influence between each pair of elements from a committee of experts. The pairwise comparison designated by following levels: $0,1,2$, and 3 to represent "No influence", "Low influence", "High influence", and "Very high influence", respectively. The initial direct-relation matrix $\boldsymbol{A}$, formatted as $A=\left[a_{i j}\right]_{n \times n}$ is a $n \times n$ matrix, in which $a_{i j}$ is denoted as the degree to which the element $i$ affects the element $j$.

\section{Step-2 Normalize the initial relation matrix to attain total-relation matrixes}

The normalized direct-relation matrix $X=\left[x_{i j}\right]$ can be obtained through Eqs. (1) and (2).

$$
\begin{aligned}
& s_{\text {max }}=\max _{i j}\left[\max 1 \leq i \leq n \sum_{j=1}^{n} a_{i j}, \max 1 \leq j \leq n \sum_{i=1}^{n} a_{i j}\right], \\
& X=\frac{1}{S} A
\end{aligned}
$$

Where $s_{\max }$ in Eq. (1) indicates the maximum values out of the sums of all the rows and the sums of all the columns; $X$ in Eq. (2) represents the normalized initial direct-relation matrix. All elements in matrix $X$ are complying with $0 \leq x_{i j} \leq 1$, and all principal diagonal 
elements are equal to 0 . The total relation matrix $T$ is obtained using the following two numerical calculations in Eqs. (3) and (4).

$$
\begin{aligned}
& T=X+X^{2}+\ldots+X^{p}=X \times(I-X)^{-1}=\left[x_{i j}\right]_{n \times n}, p \rightarrow \infty \\
& T=\left[t_{i j}\right]_{n \times n}, i, j=1,2, \ldots, n
\end{aligned}
$$

Where $I$ is the identity matrix, and $p$ represents the power. The matrix $X$ will converge when $p$ tends to infinity. Furthermore, the produced total relation matrix $T$ by DEMATEL technique is based on the comparisons among criteria; therefore, it can be renamed as total criteria relation matrix $\left(T_{c}=\left[T_{c}^{i j}\right]_{n \times n}\right)$, formatted in Eq. (5), with $m$ dimensions and $n_{1}$ to $n_{m}$ criteria.

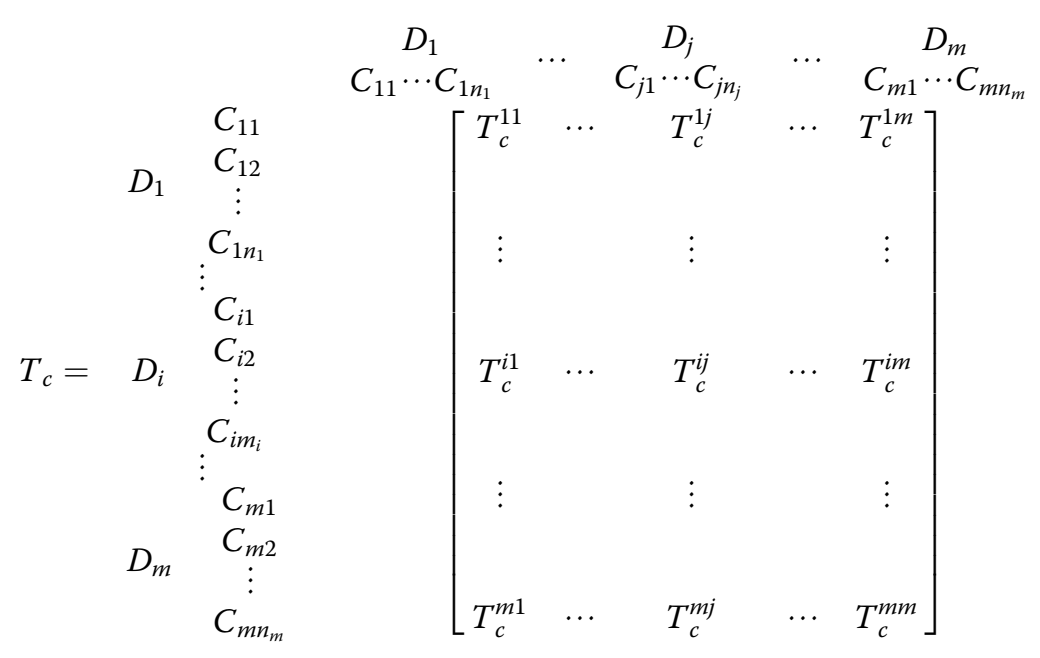

Where each $\boldsymbol{D}_{m}$ denotes the $m_{t h}$ dimension; $C_{n m}$ represents the $m_{t h}$ criteria in the $n_{t h}$ dimension; and $T_{c}^{i j}$ is the principle eigenvector of the influences of the elements in the $i_{t h}$ dimension, as compared to the $i_{t h}$ dimension. Based on above $T_{c}$, the total dimensions relation matrix $T_{d}$ is generated from total criteria matrix by Eq. (6), where $t_{d}^{i j}$ is the average of elements of matrix $T_{c}^{i j}$.

$$
T_{d}=\left[\begin{array}{ccccc}
t_{d}^{11} & \cdots & t_{d}^{1 j} & \cdots & t_{d}^{1 m} \\
\vdots & & \vdots & & \vdots \\
t_{d}^{i 1} & \cdots & t_{d}^{i j} & \cdots & t_{d}^{t_{d}} \\
\vdots & & \vdots & & \vdots \\
t_{d}^{m 1} & \cdots & t_{d}^{m j} & \cdots & t_{d}^{m m}
\end{array}\right]
$$

\section{Step-3 Generate the impact relation map}

The IRM of $T_{c}$ and $T_{d}$ is established via the vectors $r$ and $s$, and the sums of rows and columns, respectively, which are formatted as Eqs. (7) and (8).

$$
\begin{aligned}
& r=\left[r_{i}\right]_{n \times 1}=\left[\sum_{j=1}^{n} t_{i j}\right]_{n \times 1} \\
& c=\left[c_{j}\right]_{n \times 1}=\left[\sum_{i=1}^{n} t_{i j}\right]_{1 \times n}^{\prime}
\end{aligned}
$$


Where $r_{i}$ denotes the sum of the $i_{t h}$ row, representing the entire influences of criteria (or dimensions) on other criteria (or dimensions). Besides, $c_{j}$ denotes the sum of the $i_{t h}$ column of matrix $T_{c}$ (or $T_{d}$ ), meaning the total impacts that criterion (or dimension) $j$ gets from other criteria (or dimensions). In the definition of IRM, it can be constructed by mapping the dataset of the $\left(r_{i}+s_{j}, r_{i}-s_{j}\right)$. The horizontal axis vector $\left(r_{i}+s_{j}\right)$ named "Prominence" is made by adding $r_{i}$ to $s_{j}$, which shows the importance of the element. Similarly, the vertical axis $\left(r_{i}-s_{j}\right)$ named "Relation" is made by subtracting $r_{i}$ from $s_{j}$. Generally, when $\left(r_{i}-s_{j}\right)$ is positive, the element belongs to the cause group; otherwise, the element belongs to the effect group [82,83]. After calculating the means of $\left(r_{i}+s_{j}\right)$ and $\left(r_{i}-s_{j}\right)$, the IRM is divided into four quadrants. Elements in quadrant I have both high prominence and relation, which means they have highest interaction influence level with other elements; thus, they are identified as driving factors. Elements in quadrant II have low prominence but high relation, and they are identified as voluntariness. Elements in quadrant III have both low prominence and relation, and they are relatively disconnected from the system. Elements in quadrant IV have high prominence and low relation, which means they are important items impacted by other elements [84].

\section{Step-4 Normalize total criteria relation matrix}

The total criteria relation matrix $T_{c}$ is normalized by total degrees of effect and influence

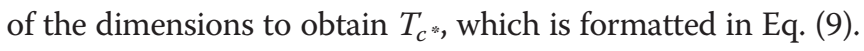

$$
\begin{aligned}
d_{c i}^{11} & =\sum_{j=1}^{m} t_{i j}^{11} i, j=1,2, \ldots, m, T_{c *}^{11}=\left[\begin{array}{ccccc}
t_{c 11}^{11} / d_{c 1}^{11} & \cdots & t_{c 1 j}^{11} / d_{c 1}^{11} & \cdots & t_{c 1 m}^{11} / d_{c 1}^{11} \\
\vdots & & & \vdots \\
t_{c i 1}^{11} / d_{c i}^{11} & \cdots & t_{c i j}^{11} / d_{c i}^{11} & \cdots & t_{c i m}^{11} / d_{c i}^{11} \\
\vdots & & & \vdots \\
t_{c m 1}^{11} / d_{c m}^{11} & \cdots & t_{c m_{j}}^{11} / d_{c m}^{11} & \cdots & t_{c m m}^{11} / d_{c m}^{11}
\end{array}\right] \\
& =\left[\begin{array}{ccccc}
t_{c 11 *}^{11} & \cdots & t_{c 1 j *}^{11} & \cdots & t_{c 1 m *}^{11} \\
\vdots & & & & \\
t_{c i 1 *}^{11} & \cdots & t_{c i j *}^{11} & \cdots & t_{c i m *}^{11} \\
\vdots & & & & \vdots \\
t_{c m 1 *}^{11} & \cdots & t_{c m j *}^{11} & \cdots & t_{c m m *}^{11}
\end{array}\right], \text { and then } T_{c *}=\left[\begin{array}{ccccc}
T_{c *}^{11} & \cdots & T_{c *}^{1 j} & \cdots & T_{c *}^{1 m} \\
\vdots & & \vdots & & \vdots \\
T_{c *}^{i 1} & \cdots & T_{c *}^{i j} & \cdots & T_{c *}^{i m} \\
\vdots & & \vdots \\
T_{c *}^{m 1} & \cdots & T_{c *}^{m j} & \cdots & T_{c *}^{m m}
\end{array}\right]
\end{aligned}
$$

Step-5 Normalize total dimensions relation matrix

The total dimensions matrix $T_{d}$ is normalized to obtain $T_{d^{*}}$, which is formatted in Eq. (10) to represent the weights of dimensions.

$$
\begin{aligned}
t_{d}^{i}=\sum_{j=1}^{m} t_{d}^{i j}, T_{d *}= & {\left[\begin{array}{ccccc}
t_{d}^{11} / t_{d}^{1} & \cdots & t_{d}^{1 j} / t_{d}^{1} & \cdots & t_{d}^{1 m} / t_{d}^{1} \\
\vdots & & \vdots & & \vdots \\
t_{d}^{i 1} / t_{d}^{i} & \cdots & t_{d}^{i j} / t_{d}^{i} & \cdots & t_{d}^{i m} / t_{d}^{i} \\
\vdots & & \vdots & & \vdots \\
t_{d}^{m 1} / t_{d}^{m} & \cdots & t_{d}^{m j} / t_{d}^{m} & \cdots & t_{d}^{m m} / t_{d}^{m}
\end{array}\right] } \\
& =\left[\begin{array}{ccccc}
T_{d *}^{11} & \cdots & T_{d *}^{1 j} & \cdots & T_{d *}^{1 m} \\
\vdots & & \vdots & & \vdots \\
T_{d *}^{i 1} & \cdots & T_{d *}^{i j} & \cdots & T_{d *}^{i m} \\
\vdots & & \vdots & & \vdots \\
T_{d *}^{m 1} & \cdots & T_{d *}^{m j} & \cdots & T_{d *}^{m m}
\end{array}\right]
\end{aligned}
$$


Step-6 Build the weighted super-matrix and obtain influential weights of elements

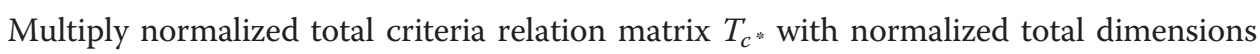
relation matrix $T_{d}$ to produce the originally weighted super-matrix $S$, which is formatted in Eq. (11). The $S$ is further transposed to a column-stochastic super-matrix $S^{*}$, which is formatted in Eq. (12).

$$
\begin{gathered}
S=\left[\begin{array}{ccccc}
T_{c *}^{11} \times T_{d *}^{11} & \cdots & T_{c *}^{1 j} \times T_{d *}^{1 j} & \cdots & T_{c *}^{1 m} \times T_{d *}^{1 m} \\
\vdots & & \vdots & & \vdots \\
T_{c *}^{i 1} \times T_{d *}^{i 1} & \cdots & T_{c *}^{i j} \times T_{d *}^{i j} & \cdots & T_{c *}^{i m} \times T_{d *}^{i m} \\
\vdots & & \vdots & & \vdots \\
T_{c *}^{m 1} \times T_{d *}^{m 1} & \cdots & T_{c *}^{m j} \times T_{d *}^{m j} & \cdots & T_{c *}^{m m} \times T_{d *}^{m m}
\end{array}\right] \\
S^{*}=\left[\begin{array}{ccccc}
T_{c *}^{11} \times T_{d *}^{11} & \cdots & T_{c *}^{i 1} \times T_{d *}^{i 1} & \cdots & T_{c *}^{m 1} \times T_{d *}^{m 1} \\
\vdots & & \vdots & & \vdots \\
T_{c *}^{1 j} \times T_{d *}^{1 j} & \cdots & T_{c *}^{i j} \times T_{d}^{i j} & \cdots & T_{c *}^{m j} \times T_{d *}^{m j} \\
\vdots & & \vdots & & \vdots \\
T_{c *}^{1 m} \times T_{d *}^{1 m} & \cdots & T_{c *}^{i m} \times T_{d *}^{i m} & \cdots & T_{c *}^{m m} \times T_{d *}^{m m}
\end{array}\right]
\end{gathered}
$$

Limit the weighted super-matrix $S^{*}$ by raising it to a sufficiently large power $\phi$ (i.e., $\left.\lim _{\phi \rightarrow \infty}\left(S^{*}\right)^{\phi}\right)$, until it converges and becomes a long-term stable super-matrix. The final global priority matrix $W=\left[W_{1}, \cdots W_{j}, \cdots W_{m}\right]$, defines the influential weights among criteria.

\section{Applications of the proposed model}

To explore the dependent and feedback nature of bicycling VCEs, this study developed a questionnaire to survey active members of bicycling VCEs, who have rich experiences in VCE participation and engagement. Based on their input, we experience the DANP analysis as follows.

\section{Representativeness of the surveyed experts Background of surveyed experts}

This study follows [62] suggestions for the qualification of research subjects to conduct the survey of interviewing domain experts in face-to-face manner to make sure the experts understand real meanings of research constructs. Table 5 lists the expert background.

\section{The appropriateness of sample size}

In terms of sample size, we adopt [64] "theoretical saturation" principle as well as consistency index of measuring EGR [65]. Based on information in Tables 6 and 7 to use four major constructs in Subsection 3.2 and the research framework in Figure 1, EGR is counted as $3.704 \%$, representing $96.296 \%$ of significant confidence on group consensus. Thus, Table 7 is suitable to be used as input data for further calculations in first part of DANP model.

\section{Implementing the empirical application of DANP analysis}

The first DANP technique is used to model an empirical application analysis of influential relationships among dimensions and criteria and to build an IRM representing these 
Table 5 Background information of experts

\begin{tabular}{|c|c|c|c|}
\hline Category/classification & No. & Category/classification & No. \\
\hline Sex & & Years of bicycling experiences & \\
\hline Male & 16 & 3 years and less & 8 \\
\hline \multirow[t]{2}{*}{ Female } & 1 & Between 4 and 6 years & 5 \\
\hline & & Greater than 7 years & 4 \\
\hline Age & & Years of bicycling VCE experiences & \\
\hline 30 years and under & 8 & 3 years and less & 4 \\
\hline \multirow[t]{2}{*}{ Between 31 and 40 years } & 9 & Between 4 and 6 years & 12 \\
\hline & & Greater than 7 years & 1 \\
\hline Education level & & Most frequent participating bicycling VCEs & \\
\hline Bachelor & 9 & Facebook & 8 \\
\hline \multirow[t]{2}{*}{ Master } & 8 & Mobile01 & 7 \\
\hline & & Other & 2 \\
\hline \multicolumn{4}{|l|}{ Years of online experiences } \\
\hline 5 years and less & 0 & & \\
\hline Between 6 and 10 years & 2 & & \\
\hline Greater than 10 years & 15 & & \\
\hline
\end{tabular}

relationships. The implementing algorithm using an empirical study is experimented systematically as follows.

\section{Step-1 Crate the initial direct-relation matrix}

Based on group consensus results, we have created initial direct-relation matrix $A$ as shown in Table 7.

\section{Step-2 Normalize the initial relation matrix to attain total-relation matrixes}

Matrix $A$ is normalized to get the matrix $X$ using Eqs. (1) and (2). Table 8 lists information of the normalized initial direct-relation matrix. The total-relation matrix $T$ is obtained

Table 6 Group consensuses of the 16 subjects on the degree of influence among the criteria

\begin{tabular}{|c|c|c|c|c|c|c|c|c|c|c|c|c|c|c|}
\hline Criteria & a1 & a2 & a3 & b1 & b2 & b3 & b4 & c1 & C2 & c3 & d1 & d2 & d3 & d4 \\
\hline a1 & 0.000 & 1.813 & 1.800 & 1.500 & 2.000 & 2.250 & 2.438 & 2.188 & 1.688 & 2.688 & 2.438 & 1.938 & 2.375 & 2.750 \\
\hline a2 & 2.750 & 0.000 & 2.750 & 1.500 & 2.500 & 1.938 & 2.000 & 1.938 & & & 2.500 & & 1.938 & 2.625 \\
\hline & 2.375 & 2.375 & 0.000 & 2.438 & 2.500 & & 1.938 & 1.563 & & & 2.250 & 2.063 & 2.688 & 3.000 \\
\hline b1 & 2.250 & 1.813 & 2.125 & 0.000 & 1.875 & 2.563 & 2.375 & 2.688 & 0.938 & 2.250 & 2.375 & & & 2.813 \\
\hline b2 & 2.500 & 1.813 & 3.000 & 1.750 & 0.000 & 2.313 & 2.313 & 1.813 & 1.688 & 2.938 & 2.750 & 1.563 & 2.813 & 2.438 \\
\hline b3 & 1.688 & 1.813 & 2.000 & 1.938 & 1.938 & 0.000 & 2.625 & 1.688 & 1.500 & 2.438 & 1.938 & & 2.250 & 2.250 \\
\hline b4 & 2.313 & 1.875 & 2.063 & 2.125 & 2.375 & 2.250 & 0.000 & 1.625 & 1.250 & 2.250 & 2.188 & 1.875 & 2.125 & 3.250 \\
\hline & 1.938 & 0.875 & 1.750 & 2.313 & 1.688 & 1.000 & 1.500 & 0.000 & 0.438 & 0.813 & 2.938 & 0.938 & 2.000 & 1.938 \\
\hline$c 2$ & 1.063 & 0.813 & 2.313 & 0.938 & 1.438 & 0.750 & 0.750 & 0.438 & 0.000 & 1.563 & 1.375 & 0.750 & 1.750 & 2.063 \\
\hline c3 & 2.188 & 2.500 & 2.688 & 2.125 & 2.875 & 1.875 & 2.750 & 0.625 & 1.563 & 0.000 & 2.813 & 1.813 & 2.938 & 2.875 \\
\hline d1 & 1.813 & 2.188 & 2.438 & 3.000 & 2.500 & 1.750 & 1.688 & 2.625 & 0.625 & 2.250 & 0.000 & 1.938 & 2.625 & 3.000 \\
\hline$d 2$ & 1.125 & 0.938 & 1.313 & 1.125 & 1.563 & 0.688 & 0.688 & 0.875 & 0.563 & 1.125 & 0.625 & 0.000 & 1.000 & 1.438 \\
\hline d3 & 1.563 & 1.875 & 1.875 & 2.063 & 2.313 & 1.563 & 1.688 & 1.500 & 1.000 & 2.688 & 1.813 & 1.438 & 0.000 & 2.250 \\
\hline d4 & 1.250 & 1.750 & 2.313 & 1.188 & 1.188 & 1.125 & 1.625 & 0.688 & 1.563 & 2.125 & 2.125 & 2.063 & 1.938 & 0.000 \\
\hline
\end{tabular}


Table 7 Group consensuses of the 17 subjects on the degree of influence among the criteria

\begin{tabular}{lllllllllllllll}
\hline Criteria & $\mathbf{a} 1$ & $\mathbf{a} 2$ & $\mathbf{a} 3$ & $\mathbf{b} \mathbf{1}$ & $\mathbf{b} \mathbf{2}$ & $\mathbf{b 3}$ & $\mathbf{b} \mathbf{4}$ & $\mathbf{c 1}$ & $\mathbf{c 2}$ & $\mathbf{c 3}$ & $\mathbf{d} \mathbf{1}$ & $\mathbf{d} \mathbf{2}$ & $\mathbf{d} \mathbf{3}$ & $\mathbf{d} \mathbf{}$ \\
\hline a1 & 0.000 & 1.882 & 1.938 & 1.647 & 2.059 & 2.353 & 2.412 & 2.235 & 1.588 & 2.765 & 2.529 & 2.059 & 2.471 & 2.824 \\
a2 & 2.765 & 0.000 & 2.647 & 1.412 & 2.412 & 1.824 & 1.882 & 2.000 & 0.765 & 2.647 & 2.471 & 1.882 & 1.824 & 2.647 \\
a3 & 2.471 & 2.294 & 0.000 & 2.529 & 2.588 & 1.882 & 2.000 & 1.706 & 2.294 & 2.706 & 2.353 & 2.118 & 2.765 & 3.059 \\
b1 & 2.235 & 1.706 & 2.235 & 0.000 & 1.882 & 2.471 & 2.353 & 2.765 & 0.941 & 2.235 & 2.353 & 1.471 & 2.176 & 2.882 \\
b2 & 2.529 & 1.765 & 3.059 & 1.765 & 0.000 & 2.294 & 2.353 & 1.765 & 1.647 & 3.000 & 2.765 & 1.647 & 2.824 & 2.529 \\
b3 & 1.706 & 1.706 & 1.941 & 1.882 & 1.941 & 0.000 & 2.529 & 1.647 & 1.471 & 2.353 & 1.882 & 2.059 & 2.176 & 2.176 \\
b4 & 2.294 & 1.765 & 2.118 & 2.118 & 2.412 & 2.176 & 0.000 & 1.706 & 1.294 & 2.294 & 2.176 & 2.000 & 2.235 & 3.294 \\
c1 & 2.059 & 1.000 & 1.765 & 2.412 & 1.647 & 1.000 & 1.588 & 0.000 & 0.412 & 0.941 & 3.000 & 0.882 & 1.941 & 2.059 \\
c2 & 1.000 & 0.765 & 2.353 & 0.941 & 1.412 & 0.765 & 0.824 & 0.412 & 0.000 & 1.588 & 1.353 & 0.824 & 1.824 & 2.176 \\
c3 & 2.294 & 2.353 & 2.765 & 2.118 & 2.941 & 1.824 & 2.824 & 0.765 & 1.588 & 0.000 & 2.824 & 1.882 & 2.941 & 2.882 \\
d1 & 1.824 & 2.176 & 2.529 & 3.000 & 2.471 & 1.706 & 1.706 & 2.706 & 0.706 & 2.294 & 0.000 & 2.000 & 2.647 & 3.000 \\
d2 & 1.176 & 0.941 & 1.412 & 1.235 & 1.588 & 0.706 & 0.824 & 0.824 & 0.588 & 1.235 & 0.647 & 0.000 & 0.941 & 1.588 \\
d3 & 1.588 & 1.765 & 1.941 & 2.059 & 2.353 & 1.529 & 1.765 & 1.529 & 1.118 & 2.706 & 1.882 & 1.353 & 0.000 & 2.294 \\
d4 & 1.412 & 1.765 & 2.412 & 1.235 & 1.294 & 1.118 & 1.706 & 0.765 & 1.529 & 2.176 & 2.059 & 2.176 & 2.000 & 0.000 \\
\hline
\end{tabular}

using Eqs. (3) and (4), and the total criteria relation matrix $T_{\mathrm{c}}$ and total dimensions relation matrix $T_{\mathrm{d}}$ are derived by Eqs. (5) and (6). Tables 9 and 10 list the total criteria relation matrix and total dimensions relation matrix separately.

\section{Step-3 Generate the impact relation map}

Subsequently, by using Eqs. (7) and (8), the total influence given and received to each dimension and criterion for IRM of $T_{c}$ and $T_{d}$ is summarized as shown in Table 11. From Table 11, we identify the prominence $\left(r_{i}+s_{j}\right)$ and cause-effect $\left(r_{i}-s_{j}\right)$ of dimensions and criteria. Putting $r_{i}+s_{j}$ as $\mathrm{X}$-axis and $r_{i}-s_{j}$ as Y-axis, we obtain IRMs of various dimensions below. Figures 3, 4, 5, 6 and 7 summarize the IRMs information of dimensions and criteria, including total dimensions, tribal behavior, perceived customer

Table 8 Normalized initial direct-relation matrix

\begin{tabular}{lllllllllllllll}
\hline Criteria & $\mathbf{a} 1$ & $\mathbf{a} 2$ & $\mathbf{a} 3$ & $\mathbf{b} 1$ & $\mathbf{b} 2$ & $\mathbf{b 3}$ & $\mathbf{b 4}$ & $\mathbf{c 1}$ & $\mathbf{c 2}$ & $\mathbf{c 3}$ & $\mathbf{d} 1$ & $\mathbf{d} 2$ & $\mathbf{d} 3$ & $\mathbf{d} 4$ \\
\hline a1 & 0.000 & 0.056 & 0.058 & 0.049 & 0.062 & 0.070 & 0.072 & 0.067 & 0.048 & 0.083 & 0.076 & 0.062 & 0.074 & 0.085 \\
a2 & 0.083 & 0.000 & 0.079 & 0.042 & 0.072 & 0.055 & 0.056 & 0.060 & 0.023 & 0.079 & 0.074 & 0.056 & 0.055 & 0.079 \\
a3 & 0.074 & 0.069 & 0.000 & 0.076 & 0.077 & 0.056 & 0.060 & 0.051 & 0.069 & 0.081 & 0.070 & 0.063 & 0.083 & 0.092 \\
b1 & 0.067 & 0.051 & 0.067 & 0.000 & 0.056 & 0.074 & 0.070 & 0.083 & 0.028 & 0.067 & 0.070 & 0.044 & 0.065 & 0.086 \\
b2 & 0.076 & 0.053 & 0.092 & 0.053 & 0.000 & 0.069 & 0.070 & 0.053 & 0.049 & 0.090 & 0.083 & 0.049 & 0.085 & 0.076 \\
b3 & 0.051 & 0.051 & 0.058 & 0.056 & 0.058 & 0.000 & 0.076 & 0.049 & 0.044 & 0.070 & 0.056 & 0.062 & 0.065 & 0.065 \\
b4 & 0.069 & 0.053 & 0.063 & 0.063 & 0.072 & 0.065 & 0.000 & 0.051 & 0.039 & 0.069 & 0.065 & 0.060 & 0.067 & 0.099 \\
c1 & 0.062 & 0.030 & 0.053 & 0.072 & 0.049 & 0.030 & 0.048 & 0.000 & 0.012 & 0.028 & 0.090 & 0.026 & 0.058 & 0.062 \\
c2 & 0.030 & 0.023 & 0.070 & 0.028 & 0.042 & 0.023 & 0.025 & 0.012 & 0.000 & 0.048 & 0.040 & 0.025 & 0.055 & 0.065 \\
c3 & 0.069 & 0.070 & 0.083 & 0.063 & 0.088 & 0.055 & 0.085 & 0.023 & 0.048 & 0.000 & 0.085 & 0.056 & 0.088 & 0.086 \\
d1 & 0.055 & 0.065 & 0.076 & 0.090 & 0.074 & 0.051 & 0.051 & 0.081 & 0.021 & 0.069 & 0.000 & 0.060 & 0.079 & 0.090 \\
d2 & 0.035 & 0.028 & 0.042 & 0.037 & 0.048 & 0.021 & 0.025 & 0.025 & 0.018 & 0.037 & 0.019 & 0.000 & 0.028 & 0.048 \\
d3 & 0.048 & 0.053 & 0.058 & 0.062 & 0.070 & 0.046 & 0.053 & 0.046 & 0.033 & 0.081 & 0.056 & 0.040 & 0.000 & 0.069 \\
d4 & 0.042 & 0.053 & 0.072 & 0.037 & 0.039 & 0.033 & 0.051 & 0.023 & 0.046 & 0.065 & 0.062 & 0.065 & 0.060 & 0.000 \\
\hline
\end{tabular}


Table 9 Total criteria relation matrix

\begin{tabular}{lllllllllllllll}
\hline Criteria & $\mathbf{a} 1$ & $\mathbf{a} 2$ & $\mathbf{a} 3$ & $\mathbf{b} \mathbf{1}$ & $\mathbf{b 2}$ & $\mathbf{b 3}$ & $\mathbf{b} \mathbf{4}$ & $\mathbf{c 1}$ & $\mathbf{c 2}$ & $\mathbf{c 3}$ & $\mathbf{d} \mathbf{1}$ & $\mathbf{d} \mathbf{2}$ & $\mathbf{d} \mathbf{3}$ & $\mathbf{d} \mathbf{4}$ \\
\hline a1 & 0.201 & 0.232 & 0.284 & 0.243 & 0.273 & 0.240 & 0.266 & 0.229 & 0.176 & 0.307 & 0.295 & 0.240 & 0.298 & 0.340 \\
a2 & 0.272 & 0.174 & 0.295 & 0.230 & 0.275 & 0.221 & 0.246 & 0.218 & 0.150 & 0.297 & 0.286 & 0.229 & 0.273 & 0.327 \\
a3 & 0.283 & 0.255 & 0.245 & 0.278 & 0.300 & 0.239 & 0.268 & 0.226 & 0.205 & 0.321 & 0.304 & 0.253 & 0.320 & 0.363 \\
b1 & 0.259 & 0.223 & 0.286 & 0.191 & 0.262 & 0.239 & 0.261 & 0.241 & 0.156 & 0.287 & 0.285 & 0.219 & 0.284 & 0.335 \\
b2 & 0.283 & 0.240 & 0.327 & 0.257 & 0.227 & 0.249 & 0.276 & 0.226 & 0.187 & 0.327 & 0.314 & 0.239 & 0.321 & 0.347 \\
b3 & 0.228 & 0.208 & 0.260 & 0.228 & 0.247 & 0.156 & 0.248 & 0.196 & 0.159 & 0.272 & 0.253 & 0.220 & 0.265 & 0.295 \\
b4 & 0.261 & 0.225 & 0.283 & 0.250 & 0.276 & 0.232 & 0.194 & 0.211 & 0.166 & 0.290 & 0.280 & 0.234 & 0.286 & 0.346 \\
c1 & 0.210 & 0.165 & 0.222 & 0.216 & 0.208 & 0.162 & 0.195 & 0.129 & 0.111 & 0.202 & 0.253 & 0.163 & 0.228 & 0.256 \\
c2 & 0.147 & 0.129 & 0.201 & 0.142 & 0.167 & 0.125 & 0.141 & 0.110 & 0.079 & 0.182 & 0.170 & 0.131 & 0.187 & 0.215 \\
c3 & 0.278 & 0.256 & 0.320 & 0.266 & 0.309 & 0.238 & 0.289 & 0.201 & 0.185 & 0.246 & 0.315 & 0.246 & 0.324 & 0.358 \\
d1 & 0.256 & 0.242 & 0.302 & 0.281 & 0.285 & 0.225 & 0.250 & 0.245 & 0.153 & 0.297 & 0.227 & 0.239 & 0.304 & 0.347 \\
d2 & 0.135 & 0.117 & 0.155 & 0.132 & 0.152 & 0.108 & 0.124 & 0.107 & 0.084 & 0.151 & 0.131 & 0.090 & 0.142 & 0.175 \\
d3 & 0.218 & 0.204 & 0.252 & 0.225 & 0.250 & 0.194 & 0.221 & 0.186 & 0.145 & 0.273 & 0.246 & 0.194 & 0.196 & 0.288 \\
d4 & 0.194 & 0.187 & 0.243 & 0.185 & 0.202 & 0.166 & 0.200 & 0.150 & 0.145 & 0.238 & 0.228 & 0.200 & 0.231 & 0.200 \\
\hline
\end{tabular}

benefits, customer participation behavior, and customer citizenship behavior, respectively. In terms of cause-effect relationship, tribal behavior (A) affects perceived customer benefits (B), customer participation behavior (C), and customer citizenship behavior (D); $\mathrm{B}$ affects $\mathrm{C}$ and $\mathrm{D}$; and $\mathrm{C}$ affects $\mathrm{D}$. In order to make uncluttered IRMs, we follow principles suggested by [62] that if there are paths from A to B and B to C, and a direct path $A$ to $C$, then the direct path is deleted. Thus, the relationships are represented as $\mathrm{A} \rightarrow\{\mathrm{B}, \mathrm{C}, \mathrm{D}\}$ that is an interesting finding.

\section{Step-4 Normalize total criteria relation matrix}

Having determined the relationship structure of all dimensions and criteria, the total criteria relation matrix was normalized according to Eq. (9), and Table 12 shows the normalized result.

\section{Step-5 Normalize total dimensions relation matrix}

The total dimensions relation matrix was normalized by Eq. (10). The normalized result is shown in Table 13.

\section{Step-6 Build the weighted super-matrix and obtain influential weights of elements}

The normalized total criteria relation matrix was weighted by the normalized total dimensions matrix to obtain an originally weighted super-matrix by Eq. (11), and

Table 10 Total dimensions relation matrix

\begin{tabular}{llllll}
\hline Dimensions & A & B & C & D & $\boldsymbol{r}_{\boldsymbol{i}}$ \\
\hline A & 0.249 & 0.257 & 0.237 & 0.294 & 1.036 \\
B & 0.257 & 0.237 & 0.226 & 0.283 & 1.003 \\
C & 0.214 & 0.205 & 0.160 & 0.237 & 0.817 \\
D & 0.209 & 0.200 & 0.181 & 0.215 & 0.805 \\
$S_{j}$ & 0.929 & 0.899 & 0.804 & 1.029 & \\
\hline
\end{tabular}


Table 11 Sum of influences given and received on dimensions and criteria

\begin{tabular}{lllll}
\hline & $\boldsymbol{r}_{\boldsymbol{i}}$ & $\boldsymbol{s}_{\boldsymbol{j}}$ & $\boldsymbol{r}_{\boldsymbol{i}}+\boldsymbol{s}_{\boldsymbol{j}}$ & $\boldsymbol{r}_{\boldsymbol{i}} \boldsymbol{s}_{\boldsymbol{j}}$ \\
\hline A & 1.036 & 0.929 & 1.966 & 0.107 \\
a1 & 3.624 & 3.227 & 6.851 & 0.397 \\
a2 & 3.494 & 2.858 & 6.353 & 0.636 \\
a3 & 3.861 & 3.676 & 7.537 & 0.186 \\
B & 1.003 & 0.899 & 1.902 & 0.105 \\
b1 & 3.530 & 3.123 & 6.652 & 0.407 \\
b2 & 3.434 & 7.254 & 0.386 \\
b3 & 3.820 & 2.794 & 6.028 & 0.441 \\
b4 & 3.234 & 3.181 & 6.713 & 0.352 \\
C & 3.533 & 0.804 & 1.621 & 0.012 \\
C1 & 2.673 & 5.393 & 0.046 \\
C2 & 0.817 & 2.101 & 4.226 & 0.024 \\
C3 & 2.719 & 3.688 & 7.520 & 0.144 \\
D & 2.125 & 1.029 & 1.833 & -0.224 \\
d1 & 3.832 & 3.587 & 7.240 & 0.066 \\
d2 & 0.805 & 2.897 & 4.700 & -1.095 \\
d3 & 3.653 & 3.659 & 6.751 & -0.567 \\
d4 & 1.802 & 4.191 & 6.959 & -1.423 \\
\hline
\end{tabular}

the matrix was then transposed to get the weighted super-matrix using Eq. (12). Table 14 describes information of the weighted super-matrix. Finally, the influential weights of criteria are obtained by limiting the power of the weighted super-matrix until it reaches a stable state. Table 15 shows the limit information on criteria.

\section{Results and discussions}

After the implemented DANP model, three types of major analytical results of this study in the context of value co-creation behavior of bicycling VCEs are described as follows. (1) Validation: The dynamic dependence and feedback nature of VCE value

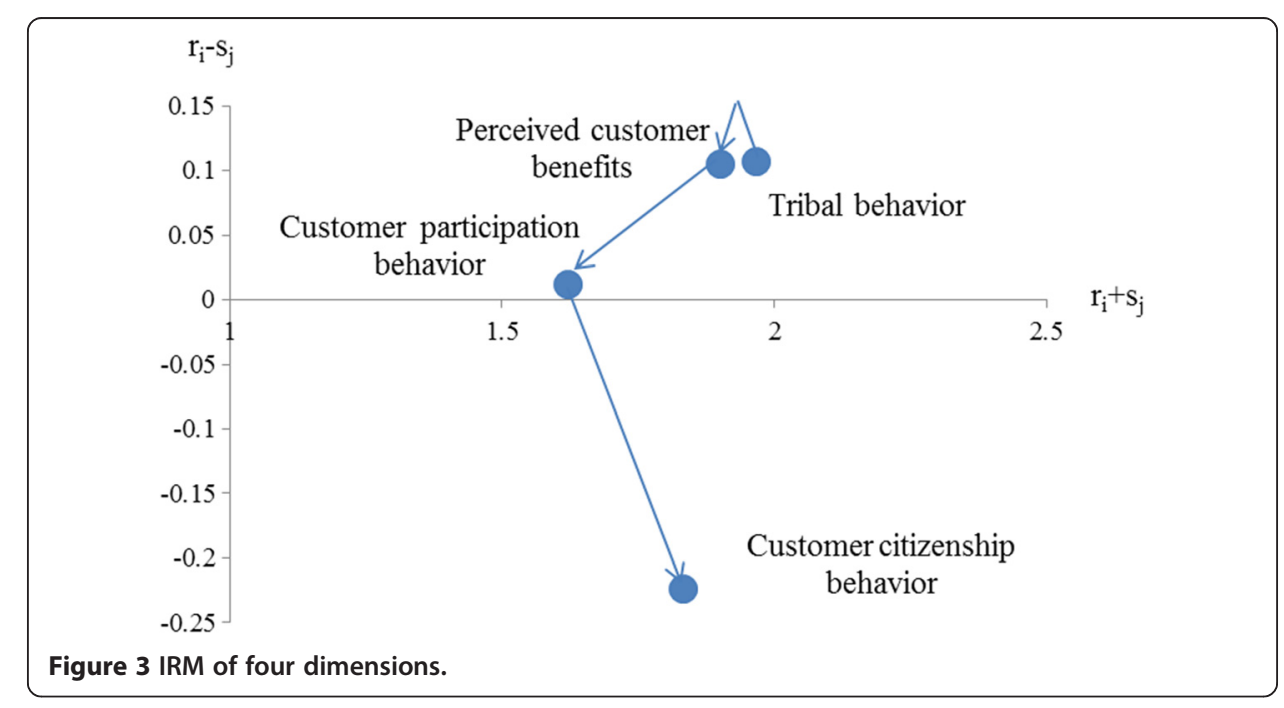




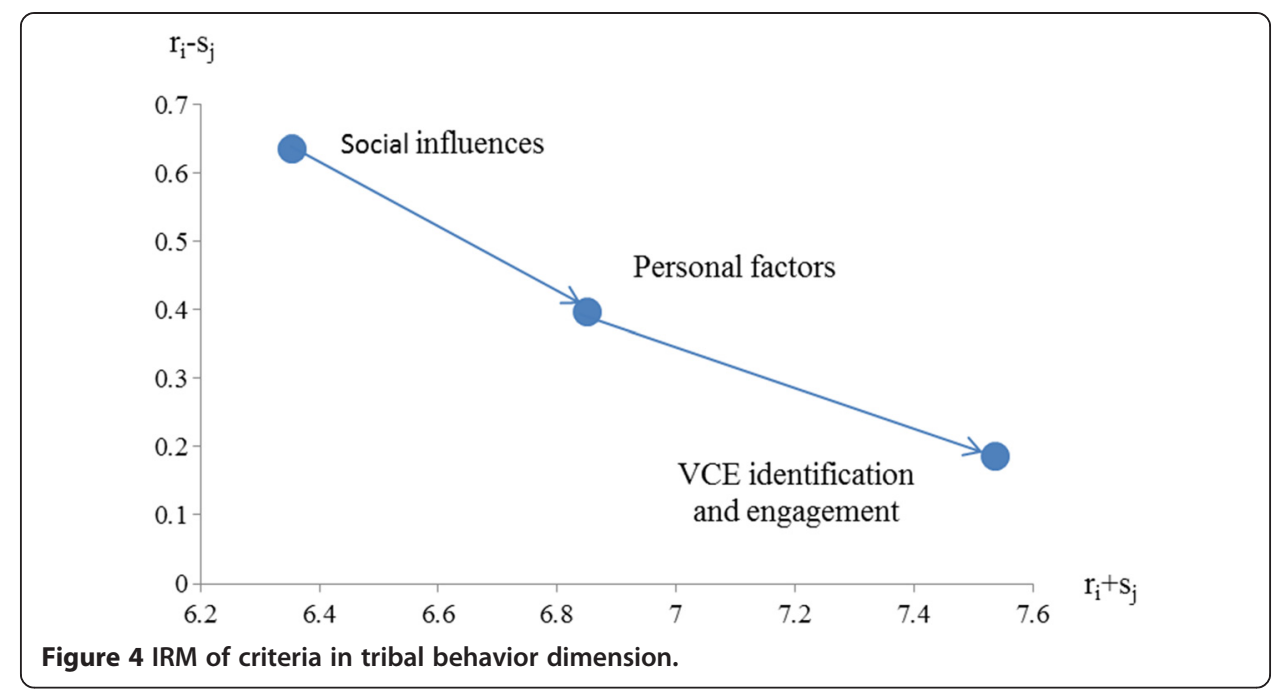

co-creation behavior are validated. As the total criteria relation matrix and total dimensions relation matrix capture the effects and influences of elements, and there is no empty cell in the matrix, all elements both influence and be influenced by other elements. This conclusion reflects the dynamic and sophisticated real world phenomena. (2) Identification: Dominant influencing trends are visually identified. Though all elements influence each other, there exist some significant relationships. We summarized driving factors of dimensions and criteria from the IRMs as shown in Table 16 below. (3) Finding: The influential weights of criteria are clearly identified in Table 17. As shown in Table 17, from global perspective, top four criteria of the system are continuance intention, personal interaction, VCE identification, and helping. Besides, priorities normalized by dimension are equally distributed in nature, which represent they have similar contributions for the system. Furthermore, the most important criteria under each dimension are recognized as VCE identification and engagement, social integrative benefits, personal interaction, and continuance intention. These findings reflect the social networking nature of bicycling VCEs.

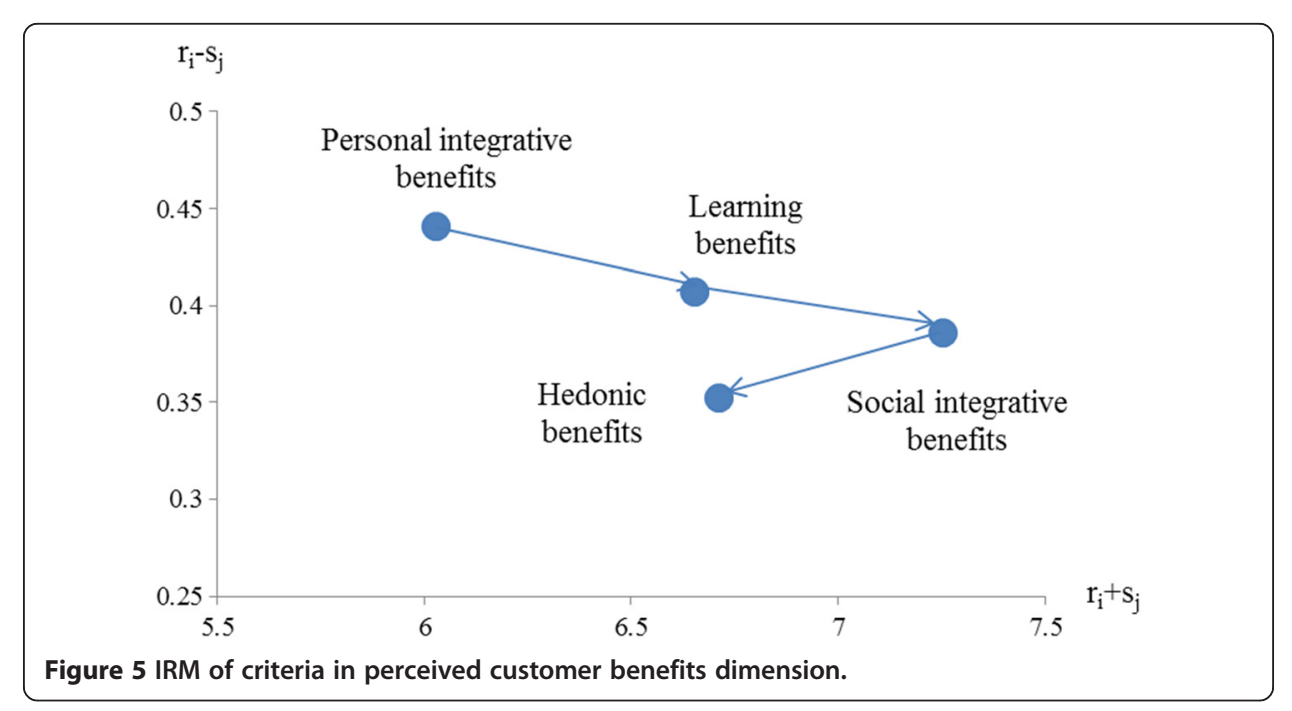




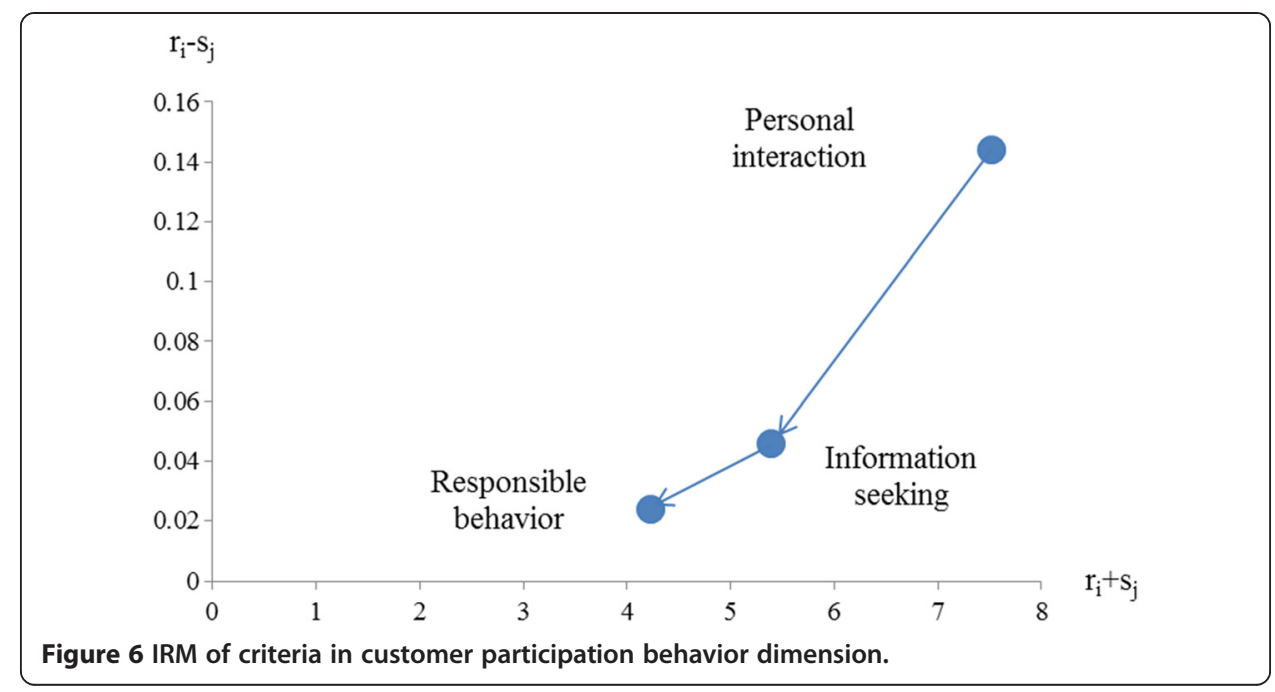

\section{Conclusion}

In this service economy era, the importance of value co-creation behavior cannot be overemphasized. Accompanying the rapid development and popularity of social networking sites and bicycling activities, the value co-creation behavior of bicycling VCEs deserve deeper investigations. To reach this end, this study used a hybrid expert-based DANP model to implement an empirical case study with the significant features as follows:

\section{U\&G framework and S-O-R model}

This study bases on U\&G framework [30] and S-O-R model [60] to combine with perspective from S-D logic to establish and validate the hybrid expert-based DANP model concerning the dynamic value co-creation behavior in bicycling VCEs. Particularly, no prior hypothesized relationships in terms of direction and degree are assumed in this model since it would be more consistent with real world cases that all factors interrelate

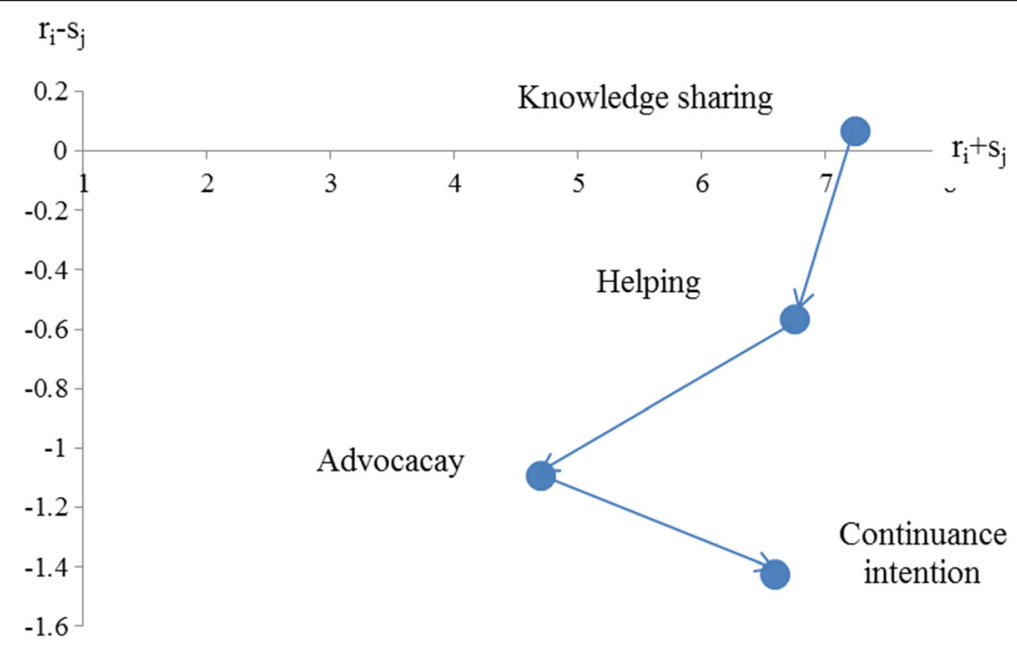

Figure 7 IRM of criteria in customer citizenship behavior dimension. 
Table 12 Normalized total criteria relation matrix

\begin{tabular}{lllllllllllllll}
\hline Criteria & $\mathbf{a} 1$ & $\mathbf{a} 2$ & $\mathbf{a} 3$ & $\mathbf{b} \mathbf{1}$ & $\mathbf{b 2}$ & $\mathbf{b 3}$ & $\mathbf{b 4}$ & $\mathbf{c 1}$ & $\mathbf{c 2}$ & $\mathbf{c 3}$ & $\mathbf{d} \mathbf{1}$ & $\mathbf{d} \mathbf{2}$ & $\mathbf{d} \mathbf{3}$ & $\mathbf{d} \mathbf{4}$ \\
\hline a1 & 0.280 & 0.324 & 0.396 & 0.237 & 0.267 & 0.235 & 0.261 & 0.322 & 0.248 & 0.431 & 0.251 & 0.204 & 0.254 & 0.290 \\
a2 & 0.367 & 0.235 & 0.398 & 0.236 & 0.283 & 0.227 & 0.253 & 0.328 & 0.226 & 0.446 & 0.257 & 0.206 & 0.245 & 0.293 \\
a3 & 0.362 & 0.326 & 0.313 & 0.256 & 0.277 & 0.220 & 0.247 & 0.300 & 0.272 & 0.427 & 0.245 & 0.204 & 0.258 & 0.293 \\
b1 & 0.338 & 0.291 & 0.372 & 0.201 & 0.275 & 0.251 & 0.273 & 0.352 & 0.228 & 0.420 & 0.254 & 0.195 & 0.253 & 0.298 \\
b2 & 0.333 & 0.283 & 0.384 & 0.255 & 0.225 & 0.247 & 0.274 & 0.306 & 0.252 & 0.442 & 0.257 & 0.196 & 0.263 & 0.285 \\
b3 & 0.328 & 0.299 & 0.373 & 0.259 & 0.281 & 0.178 & 0.283 & 0.312 & 0.254 & 0.433 & 0.245 & 0.213 & 0.257 & 0.285 \\
b4 & 0.339 & 0.293 & 0.369 & 0.262 & 0.290 & 0.243 & 0.204 & 0.317 & 0.249 & 0.434 & 0.244 & 0.204 & 0.250 & 0.302 \\
c1 & 0.352 & 0.276 & 0.372 & 0.277 & 0.266 & 0.207 & 0.250 & 0.292 & 0.251 & 0.457 & 0.281 & 0.181 & 0.253 & 0.285 \\
c2 & 0.308 & 0.270 & 0.422 & 0.247 & 0.290 & 0.217 & 0.245 & 0.296 & 0.213 & 0.491 & 0.242 & 0.187 & 0.266 & 0.306 \\
c3 & 0.325 & 0.300 & 0.375 & 0.241 & 0.281 & 0.216 & 0.262 & 0.317 & 0.293 & 0.389 & 0.253 & 0.198 & 0.261 & 0.288 \\
d1 & 0.320 & 0.303 & 0.377 & 0.270 & 0.274 & 0.216 & 0.240 & 0.353 & 0.221 & 0.427 & 0.203 & 0.214 & 0.272 & 0.310 \\
d2 & 0.331 & 0.287 & 0.381 & 0.256 & 0.294 & 0.210 & 0.240 & 0.313 & 0.245 & 0.441 & 0.244 & 0.168 & 0.263 & 0.325 \\
d3 & 0.324 & 0.302 & 0.374 & 0.253 & 0.281 & 0.218 & 0.249 & 0.308 & 0.240 & 0.451 & 0.266 & 0.210 & 0.212 & 0.312 \\
d4 & 0.311 & 0.300 & 0.389 & 0.246 & 0.269 & 0.220 & 0.265 & 0.281 & 0.272 & 0.447 & 0.265 & 0.233 & 0.269 & 0.233 \\
\hline
\end{tabular}

and influence with each other somehow. As a result, it is expected that the study findings can provide insightful and complementary contributions to related studies.

\section{Domain experts}

The subjects interviewed are domain experts who have rich experiences on the engagement of bicycling VCEs. Therefore, the responses induced from them are based on their accumulated experiences instead of judgments on specific organizations. Moreover, the qualitative and quantitative qualifications of interviewed experts were well controlled according to suggestions from qualitative research field to make sure their representativeness.

\section{Objective mathematical calculations}

The final consensuses of these experts were derived by objective mathematical calculations instead of subjective judgments. In this way, the analytical results of this study have satisfactory reliability and validity.

Accordingly, implications of major findings from the empirical study are yielded and described in the following two directions as follows.

\section{Theoretical implications}

There are the extracted four theoretical implications in this study, as follows:

Table 13 Normalized total dimensions relation matrix

\begin{tabular}{lllll}
\hline Dimensions & A & B & C & D \\
\hline A & 0.204 & 0.280 & 0.194 & 0.321 \\
B & 0.218 & 0.269 & 0.192 & 0.320 \\
C & 0.222 & 0.283 & 0.166 & 0.328 \\
D & 0.221 & 0.283 & 0.192 & 0.304 \\
\hline
\end{tabular}


Table 14 The weighted super-matrix

\begin{tabular}{lllllllllllllll}
\hline Criteria & a1 & a2 & a3 & b1 & b2 & b3 & b4 & c1 & c2 & c3 & d1 & d2 & d3 & d4 \\
\hline a1 & 0.057 & 0.075 & 0.074 & 0.074 & 0.073 & 0.072 & 0.074 & 0.078 & 0.069 & 0.072 & 0.071 & 0.073 & 0.072 & 0.069 \\
a2 & 0.066 & 0.048 & 0.066 & 0.063 & 0.062 & 0.065 & 0.064 & 0.061 & 0.060 & 0.067 & 0.067 & 0.064 & 0.067 & 0.066 \\
a3 & 0.081 & 0.081 & 0.064 & 0.081 & 0.084 & 0.081 & 0.081 & 0.083 & 0.094 & 0.083 & 0.084 & 0.084 & 0.083 & 0.086 \\
b1 & 0.067 & 0.066 & 0.072 & 0.054 & 0.068 & 0.070 & 0.070 & 0.078 & 0.070 & 0.068 & 0.076 & 0.072 & 0.072 & 0.069 \\
b2 & 0.075 & 0.079 & 0.078 & 0.074 & 0.061 & 0.075 & 0.078 & 0.075 & 0.082 & 0.080 & 0.077 & 0.083 & 0.079 & 0.076 \\
b3 & 0.066 & 0.064 & 0.062 & 0.067 & 0.066 & 0.048 & 0.065 & 0.059 & 0.062 & 0.061 & 0.061 & 0.059 & 0.062 & 0.062 \\
b4 & 0.073 & 0.071 & 0.069 & 0.073 & 0.074 & 0.076 & 0.055 & 0.071 & 0.070 & 0.074 & 0.068 & 0.068 & 0.070 & 0.075 \\
c1 & 0.062 & 0.064 & 0.058 & 0.068 & 0.059 & 0.060 & 0.061 & 0.049 & 0.049 & 0.053 & 0.068 & 0.060 & 0.059 & 0.054 \\
c2 & 0.048 & 0.044 & 0.053 & 0.044 & 0.049 & 0.049 & 0.048 & 0.042 & 0.035 & 0.049 & 0.042 & 0.047 & 0.046 & 0.052 \\
c3 & 0.084 & 0.087 & 0.083 & 0.081 & 0.085 & 0.083 & 0.084 & 0.076 & 0.082 & 0.065 & 0.082 & 0.085 & 0.087 & 0.086 \\
d1 & 0.081 & 0.082 & 0.079 & 0.081 & 0.082 & 0.078 & 0.078 & 0.092 & 0.079 & 0.083 & 0.062 & 0.074 & 0.081 & 0.081 \\
d2 & 0.066 & 0.066 & 0.065 & 0.062 & 0.063 & 0.068 & 0.065 & 0.059 & 0.061 & 0.065 & 0.065 & 0.051 & 0.064 & 0.071 \\
d3 & 0.082 & 0.079 & 0.083 & 0.081 & 0.084 & 0.082 & 0.080 & 0.083 & 0.087 & 0.085 & 0.083 & 0.080 & 0.065 & 0.082 \\
d4 & 0.093 & 0.094 & 0.094 & 0.095 & 0.091 & 0.091 & 0.097 & 0.093 & 0.100 & 0.094 & 0.094 & 0.099 & 0.095 & 0.071 \\
\hline
\end{tabular}

\section{In tribal behavior}

Under S-D logic, value co-creation network involves relationships not only between businesses and customers, but also customers and customers. Consequently, customers are not merely responders but rather active value co-creators. The customer-to-customer relationships are referred as brand tribes [25] that have been employed by companies to enhance their customers' loyalty. Brand tribes are different from traditional brand communities in that, the latter are managed by companies in a formal manner, such as membership subscription, and various rewards or incentives are offered to members. Restate, in brand tribes, customers develop loose relationships freely by themselves without any formal subscription, called tribal behavior [25], which fits the spontaneity nature of bicycling VCEs. This study has demonstrated tribal behavior drives the pursuit of benefits that are realized by VCE engagement, and

Table 15 The limit of weighted super-matrix

\begin{tabular}{|c|c|c|c|c|c|c|c|c|c|c|c|c|c|c|}
\hline Criteria & a1 & a2 & a3 & b1 & b2 & b3 & b4 & c1 & c2 & c3 & d1 & d2 & d3 & d4 \\
\hline & 0.072 & .072 & 0.072 & 0.072 & .072 & 0.072 & 0.072 & & & & & & & \\
\hline & 0.064 & 0.064 & 0.064 & 0.064 & 0.064 & 0.064 & 0.064 & 0.064 & 0.064 & 0.064 & 0.064 & 0.064 & 0.064 & 0.064 \\
\hline & 082 & .082 & 0.082 & 0.082 & 0.082 & 0.082 & .082 & 0.082 & & 0.082 & .082 & & 0.082 & .082 \\
\hline & & & & & & & & & & & & & & \\
\hline & 0.076 & & & 0.076 & & & & & & & & & & \\
\hline & 0.062 & 0.062 & 0.062 & 0.062 & 0.062 & & & & & & & & 0.062 & 0.062 \\
\hline b4 & 0.071 & 0.071 & 0.071 & 0.071 & 0.071 & 0.071 & 0.071 & 0.071 & 0.071 & & & & 071 & \\
\hline & 0.059 & 0.059 & 0.059 & 0.059 & 0.059 & 0.059 & 0.059 & 0.059 & 0.059 & 0.059 & 0.059 & & 0.059 & 0.059 \\
\hline$c 2$ & 0.047 & 0.047 & 0.047 & 0.047 & 0.047 & 0.047 & 0.047 & 0.047 & 0.047 & 0.047 & 0.047 & 0.047 & 0.047 & 0.047 \\
\hline & 0.082 & 0.082 & & 0.082 & & & & & & & 0.082 & & 82 & \\
\hline$d 1$ & 0.079 & 0.079 & 0.079 & 0.079 & 0.079 & 0.079 & 0.079 & 0.079 & 0.079 & 0.079 & 0.079 & 0.079 & 0.079 & 0.079 \\
\hline$d 2$ & 0.064 & 0.064 & 0.064 & 0.064 & 0.064 & 0.064 & 0.064 & 0.064 & 0.064 & 0.064 & 0.064 & 0.064 & 0.064 & 0.064 \\
\hline d3 & 0.081 & 0.081 & 0.081 & 0.081 & 0.081 & 0.081 & 0.081 & 0.081 & 0.081 & 0.081 & 0.081 & 0.081 & 0.081 & 0.081 \\
\hline$d 4$ & 0.092 & 0.092 & 0.092 & 0.092 & 0.092 & 0.092 & 0.092 & 0.092 & 0.092 & 0.092 & 0.092 & 0.092 & 0.092 & 0.092 \\
\hline
\end{tabular}


Table 16 Key driving factors for dimensions and criteria

\begin{tabular}{ll}
\hline Key driving factors & Secondary factors \\
\hline Tribal Behavior & $\begin{array}{l}\text { Perceived Customer benefits }>\text { Customer Participation Behavior }>\text { Customer } \\
\text { Citizenship Behavior }\end{array}$ \\
Social influences & Personal factors $>$ VCE identification and engagement \\
Personal integrative benefits & Learning benefits $>$ Social integrative benefits $>$ Hedonic benefits \\
Personal interaction & Information seeking $>$ Responsible behavior \\
Knowledge sharing & Helping $>$ Advocacy $>$ Continuance intention \\
\hline
\end{tabular}

has affected the related participation and citizenship behaviors in turn. For major bicycling VCE tribal behavior, this study has recognized the importance of social influences toward personal commitment and engagement of bicycling activities and related VCEs.

\section{In interaction-based benefits}

Under U\&G framework, there are four broad types of interaction-based benefits that individuals can derive from engagement in VCEs, including cognitive (or learning), social integrative, personal integrative, and hedonic benefits. In terms of customer value co-creation activities, traditional models have largely been focused on the outcome of the innovation (i.e., product innovation or process innovation) and adopted economic and game-theoretic perspective to describe customers' motivation

Table 17 Priorities of dimensions and criteria

\begin{tabular}{|c|c|c|c|c|}
\hline Dimensions & Criteria & $\begin{array}{l}\text { Priorities from } \\
\text { limiting matrix }\end{array}$ & $\begin{array}{l}\text { Priorities normalized } \\
\text { by dimension }\end{array}$ & $\begin{array}{l}\text { Priorities based } \\
\text { on ideal element }\end{array}$ \\
\hline \multirow[t]{3}{*}{ Tribal Behavior } & Personal factors & 0.072 & 0.329 & 0.874 \\
\hline & Social influences & 0.064 & 0.294 & 0.780 \\
\hline & $\begin{array}{l}\text { VCE identification and } \\
\text { engagement }\end{array}$ & 0.082 & 0.377 & 1.000 \\
\hline Subtotal & & 0.218 & & 0.685 \\
\hline \multirow{4}{*}{$\begin{array}{l}\text { Perceived Customer } \\
\text { benefits }\end{array}$} & Learning benefits & 0.070 & 0.250 & 0.910 \\
\hline & $\begin{array}{l}\text { Social integrative } \\
\text { benefits }\end{array}$ & 0.076 & 0.274 & 1.000 \\
\hline & $\begin{array}{l}\text { Personal integrative } \\
\text { benefits }\end{array}$ & 0.062 & 0.222 & 0.810 \\
\hline & Hedonic benefits & 0.071 & 0.254 & 0.924 \\
\hline Subtotal & & 0.279 & & 0.879 \\
\hline \multirow{3}{*}{$\begin{array}{l}\text { Customer Participation } \\
\text { Behavior }\end{array}$} & Information seeking & 0.059 & 0.314 & 0.720 \\
\hline & Responsible behavior & 0.047 & 0.249 & 0.571 \\
\hline & Personal interaction & 0.082 & 0.437 & 1.000 \\
\hline Subtotal & & 0.188 & & 0.593 \\
\hline \multirow{4}{*}{$\begin{array}{l}\text { Customer Citizenship } \\
\text { Behavior }\end{array}$} & Knowledge sharing & 0.079 & 0.251 & 0.859 \\
\hline & Advocacy & 0.064 & 0.202 & 0.693 \\
\hline & Helping & 0.081 & 0.255 & 0.875 \\
\hline & Continuance intention & 0.092 & 0.292 & 1.000 \\
\hline Subtotal & & 0.316 & & 1.000 \\
\hline
\end{tabular}

Note: Data in bold highlight significant criterion and its corresponding dimension. 
to engagement [4]. This study follows [4,6] approach to shift the focus from outcome to the value co-creation process itself. This study provides empirical support for the proposition that customers' interactions in value co-creation can itself be an important source of value [20]. Furthermore, this study has identified the cause-effect relationships of these benefits. Specifically, personal integrative motives learning, social integrative, and hedonic benefits in sequence. This finding reveals that sense of self-efficacy originated from personal integrative benefits pushes customers' pursuit of other benefits.

\section{In customer value co-creation scale}

One core concept of S-D logic is that customers are also value co-creators. Therefore, customers are active participants and collaborative partners in the value co-creation network (or service-value chain) [37]. Yi and Gong [37] posited that to capture the conceptual richness of customer value co-creation behavior, a hierarchical and multidimensional approach is needed. As such, they developed and validated a customer value co-creation scale, including two major dimensions: Customer participation behavior and customer citizenship behavior, with each dimension composed of four components. This study adapts and modifies some of its components to fit VCE unique features since this scale is developed under physical service context.

\section{In in-role and extra-role behaviors}

This study not only has confirmed the multidimensional nature of customer value co-creation behavior, but also has explored the interrelationship among related components. From the study results, customer participation behavior affects customer citizenship behavior, with personal interaction and knowledge sharing as the key driving factors. This finding is consistent with the traditional management literature on the distinction between employee in-role (or task performance) and extra-role (or context performance) behaviors. Task performance involves those expected and necessary behavior for the successful completion of service delivery. In contrast, context performance relates to voluntary and discretionary behaviors that are not necessary for the successful value co-creation. Conclusively, it is an important finding in this study that customer participation behavior is the antecedent of customer citizenship behavior.

\section{Managerial implications}

From social-technical point of view, for most firms, the critical challenge in customer value co-creation will not be in the implementation of a technological infrastructure, but in maintaining a supportive innovative experience environment for their customers. This study yields management implications for firms focused on bicycling customers' interactions in VCEs in bicycling industry.

\section{Enhancing customer value co-creation management}

Firms should fully acknowledge the importance of VCEs in enhancing customer experience management and value co-creation. Literature confirms the tremendous contributions of VCEs to product design, testing, and support activities $[3,4,6]$. The strategic significance of 
endeavors to co-opt customer competencies for innovative value co-creation is evident [1]. Therefore, firms should work hard to enhance the linkage and interaction between participants and internal product groups. Firms can consider implementing physical organizational support, such as new organizational units or positions to manage the VCE initiative formally. The involvement of such employees creates several benefits for both firms and customers. Such organizational actions demonstrate the commitment of the firm to co-op with their customers to create win-win benefits for all involved parties. Furthermore, more advanced product can be introduced to VCE interactions and thereby enhance the product content as well as quality of interactions.

\section{Integrating both online and offline interactions}

Due to the essential driving role of tribal behavior for participation and value co-creation in VCEs, firms can take efforts to push wider acceptance of bicycling and participation of related VCEs. As this study has demonstrated social influences affects further personal and VCE beliefs and behaviors, firms can promote event marketing to increase the visibility of bicycling and combine customers' VCE interactions with appropriate off-line activities and interactions to enhance their overall experience. Reference group can also be created for positive word-of-mouth of bicycling. These activities integrate both online and offline interactions, which may further create great potential synergy for businesses.

\section{Highlighting customer perceived benefits}

Our findings highlight the importance of customer perceived benefits, since customers' active engagement in VCEs is strongly influenced by their perception regarding possible benefits. Therefore, firms should take active measures to enhance the contributions of such benefits. For personal integrative benefits, firms can devise effective incentives, such as premium status for active participants to encourage more contributions and sense of self-efficacy that increase the perceptions of personal integrative benefits. Next, for learning benefits, the involvement of employees in VCEs can increase the breadth and width of product related knowledge interchanged, thereby providing opportunities for capturing more learning benefits. For social integrative benefits, the event marketing mentioned-above combined with offline gathering of VCE member can help establish good relationships to facilitate psychological attachment to the VCE, and then increase sense of belonging as social integrative benefits. Finally, hedonic benefits of VCEs may originate from pleasant experiences in conversing with one another about common interested focal issues [34], or the problem solving ability may also be a source of mental stimulation that forms another type of hedonic benefits [6]. Hence, different customer perceived benefits can complement each other. Nevertheless, firms can improve the interface and usability of VCEs to strengthen customers' aesthetic and pleasurable experiences.

\section{Taking proactive measures}

For the critical dependent constructs of this study, customers' value co-creation behaviors, including participation behavior and citizenship behavior, firms should not assume that when they established the supportive technological infrastructure, customers will join and 
support one another voluntarily. Based on our findings, customers' value co-creation behaviors are strongly influenced by their perceived potential benefits. Consequently, it is essential for firms to take proactive measures to sustain and cultivate VCEs that would contribute all four types of customer benefits adopted in our research model.

\section{Limitations and suggestions for future research}

There exist certain limitations associated with present study, and some of the limitations point to promising direction for further research. First, this study focuses on bicycling VCEs; thus, the insights gained here may not be appropriate for other context, which means the generalizations of findings may be limited. Future studies could focus on other types of VCEs, such as product design or testing-based ones, to check whether research constructs indicate different cause-effect and relative impact patterns. Another study limitation relates to the shortage of focus on website characteristics, such as information system success beliefs (i.e., information quality, system quality, and service quality), or technology acceptance beliefs (i.e., perceived usefulness, perceived ease of use, and perceived entertainment). Similarly, given the scope of present study, several customer psychological variables, such as personal innovativeness and computer self-efficacy, were not considered in the study model. Nevertheless, the influences of external interactions, and the relationship between customers' value co-creation behaviors and purchase related decision are all worth further explorations.

\section{Competing interests}

The authors declare that they have no competing interests.

\section{Authors' contributions}

The work was a result of equal contribution to the content of this paper by each of the authors. Both authors read and approved the final manuscript.

\section{Acknowledgement}

We would like to thank the reviewers for their valuable comments.

\section{Author details}

${ }^{1}$ Department of Information Management, National Yunlin University of Science and Technology, 123, University Rd., Section 3, Douliou, Yunlin 640, Taiwan. '2Department of Information Management, Hwa Hsia University of Technology, 111, Gong Jhuan Rd., Chung Ho District, New Taipei City 235, Taiwan.

Received: 6 January 2015 Accepted: 22 March 2015

Published online: 17 April 2015

References

1. Vargo SL, Lusch RF (2004) Evolving to a new dominant logic for marketing. J Mark 68(1):1-17

2. Vargo SL, Lusch RF (2008) From goods to service(s): Divergences and convergences of logics. Ind Mark Manag 37(3):254-259

3. Nambisan S (2002) Designing virtual customer environments for new product development: Toward a theory. Acad Manag Rev 27(3):392-413

4. Nambisan S, Baron RA (2007) Interactions in virtual customer environments: Implications for product support and customer relationship management. J Interact Mark 21(2):42-62

5. Porter CE, Devaraj S, Sun D (2013) A test of two models of value creation in virtual communities. J Manag Inf Syst 30(1):261-292

6. Nambisan S, Baron RA (2009) Virtual customer environments: Testing a model of voluntary participation in value co-creation activities. J Prod Innov Manag 26(4):388-406

7. Finch BJ (1999) Internet discussions as a source for consumer product customer involvement and quality information: An exploratory study. J Oper Manag 17(5):535-556

8. Algesheimer R, Dholakia UM, Herrmann A (2005) The social influence of brand community: Evidence from European car clubs. J Mark 69(3):19-34

9. Lusch RF, Vargo SL, Wessels G (2008) Toward a conceptual foundation for service science: Contributions from service-dominant logic. IBM Syst J 47(1):5-14

10. Constantin JA, Lusch RF (1994) Understanding Resource Management: How to Deploy Your People, Products, and Processes for Maximum Productivity. Planning Forum; Burr Ridge, III.: Irwin Professional Pub, Oxford, Ohio 
11. Vivek SD, Beatty SE, Morgan RM (2012) Customer engagement: Exploring customer relationships beyond purchase. J Marketing Theory Prac 20(2):122-146

12. Sedley R (2010) The $4^{\text {th }}$ Annual Online Customer Engagement Survey Report 2010. http://issuu.com/richardsedley/ docs/customer-engagement-report2010

13. Wagner C, Majchrzak A (2007) Enabling customer-centricity using wikis and the wiki way. J Manag Inf Syst 23(3):17-43

14. Brodie RJ, Hollebeek LD, Jurić B, llić A (2011) Customer engagement: conceptual domain, fundamental propositions, and implications for research. J Serv Res 14(3):252-271

15. Compeau DR, Higgins CA (1995) Computer self-efficacy: Development of a measure and initial test. MIS Q 19(2):189-211

16. Strauss J, Frost R (2013) E-Marketing. Pearson Prentice Hall, Upper Saddle River, NJ

17. Morgan RM, Hunt SD (1994) The commitment-trust theory of relationship marketing. J Mark 58(3):20-38

18. Prahalad CK, Ramaswamy V (2000) Co-opting customer competence. Harv Bus Rev 78(1):79-90

19. Prahalad CK, Ramaswamy V (2002) The co-creation connection. Strategy Bus 27:50-61

20. Prahalad CK, Ramaswamy V (2004) Co-creation experiences: The next practice in value creation. J Interact Mark 18(3):5-14

21. Algesheimer R, Dholakia PM (2006) Do customer communities pay off? Harv Bus Rev 84(11):26-30

22. Jevons C, Gabbott M, De Chernatony L (2005) Customer and brand manager perspectives on brand relationships: A conceptual framework. J Prod Brand Manage 14(5):300-309

23. Veloutsou C (2009) Brands as relationship facilitators in consumer markets. Mark Theory 9(1):127-130

24. Cova B, Pace S (2006) Brand community of convenience products: New forms of customer empowerment - the case "my Nutella The Community". Eur J Mark 40(9/10):1087-1105

25. Tsiotsou RH (2013) The role of brand relationships and tribal behavior on brand loyalty. AMA Winter Educ Conference Proc 24:366-374

26. Bazaki E, Veloutsou C (2010) Brand communities, subcultures of consumption, neo-tribes: A mélange of terminology. In: Christodoulides G, Veloutsou C, Jevons C, de Chernatony L, Papadopoulos N (eds) Contemporary Issues in Brand Research. Athens Institute for Education and Research, Athens, Greece, pp 163-180. ISBN 9789606672682

27. Hamilton $K$, Hewer P (2010) Tribal mattering spaces: Social-networking sites, celebrity affiliations, and tribal innovations J Mark Manag 26(3-4):271-289

28. Tsiotsou R, Veloutsou C (2012) Tribe: Measuring tribal behavior in service brands. In: MA SERVSIG 2012 International Service Research Conference, 7-9 June 2012, Helsinki, Finland.

29. Veloutsou C, Moutinho L (2009) Brand relationships through brand reputation and brand tribalism. J Bus Res 62(3):314-322

30. Katz E, Blumler JG, Gurevitch M (1974) Utilization of mass communication by the individual. The uses of mass communications. Cur Perspec Gratifications Res 3:19-32

31. Palmgreen P (1984) The uses and gratifications approach: Theoretical perspectives and practical relevance. Rundfunk und Fernsehen 32(1):51-62

32. Rothaermel FT, Sugiyama S (2001) Virtual internet communities and commercial success: Individual and community-level theory grounded in the atypical case of TimeZone.com. J Manag 27(3):297-312

33. Wasko MM, Faraj S (2005) Why should I share? Examining social capital and knowledge contribution in electronic networks of practice. MIS Q 29(1):35-57

34. Muniz AM Jr, O'guinn TC (2001) Brand community. J Consum Res 27(4):412-432

35. Borman WC, Motowidlo SM (1993) Expanding the criterion domain to include elements of contextual performance. In: Schmitt N, Borman WC (eds) Personnel Selection in Organizations. Jossey-Bass, San Francisco, pp 71-98

36. Yi Y, Gong T (2008) The effects of customer justice perception and affect on customer citizenship behavior and customer dysfunctional behavior. Ind Mark Manag 37(7):767-783

37. Yi Y , Gong T (2013) Customer value co-creation behavior: Scale development and validation. J Bus Res 66(9):1279-1284

38. Yi Y, Nataraajan R, Gong T (2011) Customer participation and citizenship behavioral influences on employee performance, satisfaction, commitment, and turnover intention. J Bus Res 64(1):87-95

39. Kellogg DL, Youngdahl WE, Bowen DE (1997) On the relationship between customer participation and satisfaction: Two frameworks. Int I Serv Ind Manag 8(3):206-219

40. Ennew CT, Binks MR (1999) Impact of participative service relationships on quality, satisfaction and retention: An exploratory study. J Bus Res 46(2):121-132

41. Bettencourt LA (1997) Customer voluntary performance: Customers as partners in service delivery. J Retail 73(3):383-406

42. Grönroos C (1984) A service quality model and its marketing implications. Eur J Mark 18(4):36-44

43. Barnes JG (1994) Close to the customer: But is it really a relationship? J Mark Manag 10(7):561-570

44. Lengnick-Hall CA, Claycomb VC, Inks LW (2000) From recipient to contributor: Examining customer roles and experienced outcomes. Eur J Mark 34(3/4):359-383

45. Alavi M, Leidner DE (2001) Review: Knowledge management and knowledge management systems: Conceptual foundations and research issues. MIS Q 25(1):107-136

46. Davenport TH, Prusak L (1998) Working Knowledge: Managing What Your Organization Knows. Harvard Business School Press, Boston, MA

47. Organ DW, Konovsky M (1989) Cognitive versus affective determinants of organizational citizenship behavior J Appl Psychol 74(1):157-164

48. Shtykh RY, Jin Q (2011) A human-centric integrated approach to web information search and sharing Human-Centric Comput Inform Sci 1(1):1-37, article 2

49. Chorianopoulos K (2013) Collective intelligence within web video. Human-Centric Comput Inform Sci $3(1): 1-16$, article 10

50. Ahn J, Han R (2012) An indoor augmented-reality evacuation system for the Smartphone using personalized Pedometry. Human-Centric Comput Inform Sci 2(1):1-23, article 18 
51. Malkawi MI (2013) The art of software systems development: Reliability, Availability, Maintainability, Performance (RAMP). Human-Centric Comput Inform Sci 3(1):1-17, article 22

52. Benlamri R, Zhang X (2014) Context-aware recommender for mobile learners. Human-Centric Comput Inform Sci 4(1):1-34, article 12

53. Groth M, Mertens DP, Murphy RO (2004) Customers as good soldiers: Extending organizational citizenship behavior research to the customer domain. In: Turnipseed, DL (eds) Handbook of Organizational Citizenship Behavior, Nova Science Publishers, Hauppauge, NY, pp 411-430.

54. Katz E, Lazarsfeld PF (1955) Personal Influence: The Part Played by People in the Flow of Mass Communications, The Free Press, NY

55. Bone PF (1995) Word-of-mouth effects on short-term and long-term product judgments. J Bus Res 32(3):213-223

56. Bickart B, Schindler RM (2001) Internet forums as influential sources of consumer information. J Interact Mark 15(3):31-40

57. Hennig-Thurau T (2004) Customer orientation of service employees: Its impact on customer satisfaction, commitment, and retention. Int J Serv Ind Manag 15(5):460-478

58. Rosenbaum MS, Massiah CA (2007) When customers receive support from other customers: Exploring the influence of intercustomer social support on customer voluntary performance. J Serv Res 9(3):257-270

59. Bhattacherjee A (2001) Understanding information systems continuance: An expectation-confirmation model. MIS Q 25(3):351-370

60. Mehrabian A, Russell JA (1974) An Approach to Environmental Psychology. MIT Press, Cambridge, MA

61. Dyer R, Forman E (1991) An Analytic Approach to Marketing Decisions. Prentice Hall, Englewood Cliffs

62. Northcutt N, McCoy D (2004) Interactive Qualitative Analysis: A Systems Method for Qualitative Research. Sage Publications, Thousand Oaks, CA

63. Denzin NK, Lincoln YS (1998) The Landscape of Qualitative Research: Theories and Issues. Sage Publications, Thousand Oaks, CA

64. Strauss A, Corbin J (2007) Basics of Qualitative Research: Techniques and Procedures for Developing Grounded Theory. Sage Publications, Thousand Oaks, CA

65. Chiu WY, Tzeng GH, Li HL (2013) A new hybrid MCDM model combining DANP with VIKOR to improve e-store business. Knowl-Based Syst 37:48-61

66. Chen YS, Cheng CH (2013) Hybrid models based on rough set classifiers for setting credit rating decision rules in the global banking industry. Knowl-Based Syst 39:224-239

67. Chen YS (2012) Classifying credit ratings for Asian banks using integrating feature selection and the CPDA-based rough sets approach. Knowl-Based Syst 26:259-270

68. de Andrés J, Landajo M, Lorca P (2012) Bankruptcy prediction models based on multinorm analysis: An alternative to accounting ratios. Knowl-Based Syst 30:67-77

69. Lin F, Yeh CC, Lee MY (2011) The use of hybrid manifold learning and support vector machines in the prediction of business failure. Knowl-Based Syst 24(1):95-101

70. Stahl F, Bramer M (2012) Jmax-pruning: A facility for the information theoretic pruning of modular classification rules. Knowl-Based Syst 29:12-19

71. Gabus A, Fontela E (1972) World Problems, an Invitation to Further Thought Within the Framework of DEMATEL. Battelle Geneva Research Centre, Switzerland, Geneva

72. Gabus A, Fontela E (1973) Perceptions of the World Problematique: Communication Procedure, Communicating With Those Bearing Collective Responsibility. Battelle Geneva Research Centre, Switzerland, Geneva

73. Tseng ML (2009) A causal and effect decision making model of service quality expectation using grey-fuzzy DEMATEL approach. Expert Syst Appl 36(4):7738-7748

74. Shieh JI, Wu HH, Huang KK (2010) A DEMATEL method in identifying key success factors of hospital service quality. Knowl-Based Syst 23(3):277-282

75. Tzeng GH, Chiang CH, Li CW (2007) Evaluating intertwined effects in e-learning programs: A novel hybrid MCDM model based on factor analysis and DEMATEL. Expert Syst Appl 32(4):1028-1044

76. Chen JK, Chen I (2010) Using a novel conjunctive MCDM approach based on DEMATEL, fuzzy ANP, and TOPSIS as an innovation support system for Taiwanese higher education. Expert Syst Appl 37(3):1981-1990

77. Jerry Ho WR, Tsai CL, Tzeng GH, Fang SK (2011) Combined DEMATEL technique with a novel MCDM model for exploring portfolio selection based on CAPM. Expert Syst Appl 38(1):16-25

78. Chang B, Chang CW, Wu CH (2011) Fuzzy DEMATEL method for developing supplier selection criteria. Expert Syst Appl 38(3):1850-1858

79. Saaty TL (1996) Decision Making With Dependence and Feedback: The Analytic Network Process. Rws Publications, NY

80. Chen FH, Hsu TS, Tzeng GH (2011) A balanced scorecard approach to establish a performance evaluation and relationship model for hot spring hotels based on a hybrid MCDM model combining DEMATEL and ANP. Int J Hosp Manag 30(4):908-932

81. Hung YH, Huang TL, Hsieh JC, Tsuei HJ, Cheng CC, Tzeng GH (2012) Online reputation management for improving marketing by using a hybrid MCDM model. Knowl-Based Syst 35:87-93

82. Wu WW (2008) Choosing knowledge management strategies by using a combined ANP and DEMATEL approach. Expert Syst Appl 35(3):828-835

83. Wu WW, Lee YT (2007) Developing global managers' competencies using the fuzzy DEMATEL method. Expert Syst Appl 32(2):499-507

84. Lee YC, Li ML, Yen TM, Huang TH (2010) Analysis of adopting an integrated decision making trial and evaluation laboratory on a technology acceptance model. Expert Syst Appl 37(2):1745-1754 